\title{
U⿱宀⿻三丨口
}

\section{Negotiating relevance in pre-operative assessments}

Benwell, B., \& Rhys, C. S. (2018). Negotiating relevance in pre-operative assessments. Social Science and Medicine, 200(0), 218-226. https://doi.org/10.1016/j.socscimed.2018.01.034

Link to publication record in Ulster University Research Portal

\section{Published in:}

Social Science and Medicine

Publication Status:

Published (in print/issue): 31/03/2018

DOI:

10.1016/j.socscimed.2018.01.034

\section{Document Version}

Author Accepted version

\section{General rights}

Copyright for the publications made accessible via Ulster University's Research Portal is retained by the author(s) and / or other copyright owners and it is a condition of accessing these publications that users recognise and abide by the legal requirements associated with these rights.

\section{Take down policy}

The Research Portal is Ulster University's institutional repository that provides access to Ulster's research outputs. Every effort has been made to ensure that content in the Research Portal does not infringe any person's rights, or applicable UK laws. If you discover content in the Research Portal that you believe breaches copyright or violates any law, please contact pure-support@ulster.ac.uk. 
Science \& Medicine

Manuscript Number: SSM-D-17-01203R2

Title: Negotiating relevance in pre-operative assessments

Article Type: Research paper

Keywords: UK; Conversation Analysis; troubles-telling; nurse-patient interaction.

Corresponding Author: Dr. Catrin S. Rhys,

Corresponding Author's Institution: Ulster University

First Author: Bethan Benwell

Order of Authors: Bethan Benwell; Catrin S. Rhys

Manuscript Region of Origin: UNITED KINGDOM

Abstract: Preoperative assessments provide an essential clinical risk assessment aimed at identifying patient risks and requirements prior to surgery. As such they require effective and sensitive informationgathering skills. In addition to physical examination, the preoperative assessment includes a series of routine questions assessing a patient's fitness for surgery. These questions are typically designed to elicit minimal, 'no problem' responses, but patients sometimes produce expanded responses that extend beyond the projected information. Our analysis reveals that troubles-telling is often invoked by both nurses and patients as an effective, patient-centred resource for negotiating the medical relevance of patients' concerns in these contexts.

Accepted refereed manuscript of:

Benwell B \& Rhys CS (2018) Negotiating relevance in pre-operative assessments, Social Science and Medicine, 200, pp. 218-226.

DOI : $10.1016 / j . s o c s c i m e d .2018 .01 .034$

(C) 2018, Elsevier. Licensed under the Creative Commons AttributionNonCommercial-NoDerivatives 4.0 International

http://creativecommons.org/licenses/by-nc-nd/4.0/ 


\section{Response to Reviewers}

We are delighted to see that the reviewers have accepted the manuscript as is and require no further amendments. We would like to thank the reviewers for their detailed and constructive reviews.

As per editor's requirements, we have reinserted identifying information in the manuscript.

Many thanks.

\section{$\underline{\text { Reviewers' comments }}$}

Reviewer \#1: The authors have taken into account all the points I made in my review and have skillfully edited/amended the paper so that it now makes a strong and coherent analytic argument, which it was my pleasure to read. I have no further recommendations for revision.

Reviewer \#3: The authors' revision and responses to comments are reasonable. 
Negotiating relevance in pre-operative assessments

Bethan Benwell (University of Stirling)

Catrin S. Rhys (Ulster University)

\section{Corresponding author:}

Catrin S. Rhys

School of Communication \& Media

Institute for Research in Social Sciences

Ulster University

Shore Road

Newtownabbey

Co. Antrim

BT37 0QB

cs.rhys@ulster.ac.uk 


\section{Negotiating relevance in pre-operative assessments}

Bethan Benwell (University of Stirling)

Catrin S. Rhys (Ulster University)

We would like to acknowledge the financial support of the University of Stirling Research and Enterprise Support Scheme. We are also grateful to the anonymous reviewers of this paper for their detailed and constructive reviews. 


\section{Highlights}

- In preoperative assessments, questions are typically checklist oriented.

- Patients don't always respond within the constraints of checklist questioning.

- Nurses \& patients use troubles-telling as a resource for negotiating relevance.

- Troubles-telling is a patient-centred resource for curtailing unnecessary detail. 


\section{Negotiating relevance in pre-operative assessments}

\section{ABSTRACT}

Preoperative assessments provide an essential clinical risk assessment aimed at identifying patient risks and requirements prior to surgery. As such they require effective and sensitive information-gathering skills. In addition to physical examination, the preoperative assessment includes a series of routine questions assessing a patient's fitness for surgery. These questions are typically designed to elicit minimal, 'no problem' responses, but patients sometimes produce expanded responses that extend beyond the projected information. Our analysis reveals that troubles-telling is often invoked by both nurses and patients as an effective, patient-centred resource for negotiating the medical relevance of patients' concerns in these contexts.

Key words: UK; Conversation Analysis; troubles-telling; nurse-patient interaction. 


\section{INTRODUCTION}

The preoperative assessment (POA) exists in most healthcare systems and is completed prior to planned surgery to ensure that the patient is fully informed about the upcoming procedure and that potential risks for surgery are properly assessed. The POA is part of a perioperative system of care aimed at monitoring and mitigating the associated health and mortality risks as well as reducing cancellations, shortening 'patient pathways' to treatment and speeding up post-surgery recovery, all of which in turn improve resource efficiencies (Findlay et al, 2011; Malley et al, 2015).

A range of healthcare professionals may carry out the POA, though in the UK, the role is increasingly allocated to specially trained nurses (Abraham, 2013), who are particularly suited to the communicative / therapeutic demands of the role (Bramhall, 2002; Mottram, 2009).

The POA involves a medical examination and assessment of the patient's suitability for surgery approximately three weeks before an operation. It comprises routine procedures such as measuring blood pressure and carrying out ECGs, as well as questions about the history of the patient's health (especially previous surgery/anaesthetics), and about current medication and conditions. Determining fitness for surgery is crucial for patients at risk of adverse outcomes, hence communication is key for the efficacy of POAs (Chan et al, 2011). Poor communication can contribute to, or cause, adverse events in treatment (Lingard et al, 2008) and can exacerbate patient anxiety (Carr et al, 2006; Gilmartin \& Wright, 2008). Good communication can reduce patient anxiety prior to surgery (Mottram, 2009; Chan et al, 2011), help manage patient expectations and identify their needs (Malley et al, 2015). 
The studies above focus on the communicative role of nurse practitioners in POAs, and often identify their success in providing a 'holistic' service of care (Hines et al, 2013: 74), preparing patients psychologically, and identifying potential risks through the gathering of accurate and full data. However, very little existing research on communication in the POA addresses actual interactional data (though see Benwell \& McCreaddie, (2016); also Jones, (e.g. 2007) on similar hospital admissions processes). The current study opens up this interactional 'black box' to closer analytical scrutiny by using conversation analysis to examine exchanges between nurses and patients in the UK health system. Our analysis reveals strategies for efficiently and empathically gathering relevant information from potentially anxious patients. We focus specifically on sequences in which patients give expanded responses to the checklist questions posed by the nurses. Our analysis examines how nurse and patient collaboratively negotiate the relevance of the patient's expanded response to the immediate institutional agenda of assessing fitness for surgery.

\section{Questioning in medical interaction}

Interaction in POAs shares with other medical interactions the property of being a highly question-driven form of interaction (Roter \& Hall, 2006; Stivers \& Majid, 2007). Questions set the agenda for the patient in relation to both the topical domain and the type of action expected in the response (Stivers \& Heritage, 2001). In their design, questions also embody the medical professional's presuppositions vis-à-vis the patient and their epistemic stance towards the information solicited in the question, as well as setting a preference for the polarity of the response (Heritage, 2010). For example, a question about asthma designed as “you don't have asthma do you" (Heritage, 2010: 57) seeks confirmation (through the tag 
question) of a relatively confident assumption about the patient not having asthma (the epistemic stance displayed by the declarative formatting).

These issues of question design are also influenced by the type of medical encounter (e.g. 'well visits' vs 'acute visits') and the stage of the medical encounter (e.g. history taking vs diagnosis). Heritage (2010) explains how they are differently influenced by two key principles: optimisation (Heritage, 2002) and problem attentiveness (Stivers, 2007). Optimisation refers to the observation that unless a physician has reason to believe otherwise, they typically formulate their questions to favour "“no problem" responses' (Boyd \& Heritage, 2006: 162). This is illustrated in the example above, in which the doctor's question is grammatically designed to favour a 'no asthma' response. Boyd \& Heritage (2006) show that this is the default principle of medical questioning, evident during medical history taking and routine information gathering appointments (with the notable exception of lifestyle questions relating to smoking and drinking, which are rarely optimised (Heritage, 2010)). In contrast, in acute visits, patients present with a problem for which diagnosis/treatment is sought. In these contexts, problem attentiveness dictates that questions relating to the patient's primary symptoms are designed to presuppose a problem. In the POA, diagnosis/treatment has already been addressed; the function of the POA is to determine that there are no additional concerns that might prevent surgery taking place. In other words, the patient's current health problem is not the focus of the questioning. Thus, the design of the nurses' questions is not typically problem-attentive but rather is oriented to optimised information gathering.

An additional factor in information gathering/medical history taking is orientation to the routine, 'checklist' nature of the interactional task where the content of the questions is 
governed by a procedure or even an actual form to be filled in. This has consequences for the design of the questions and also for the opening sequence. Specifically, health visitors (Heritage \& Sefi, 1992; Raymond, 2010) and nurses (Jones, 2007) are observed to preface the questioning with reference to the bureaucratic, imposed nature of the task. In addition, successive questions are often linked through and-prefacing (Heritage \& Sorjonen, 1994) or a reduced grammatical form that is anaphorically dependent on the preceding question (Stivers \& Heritage, 2001) and marks the question as one in a 'checklist series' of questions.

In all this, Heritage (2010: 46) observes that 'physicians and patients both cooperate and struggle with one another over "what matters" in a given medical context'. In other words, whilst the health professional ultimately decides what information will be recorded on the form, in designing and responding to the questions, both parties are involved in negotiating the value of the information exchanged in relation to the institutional goals of the medical encounter.

Our analysis shows that POA questioning involves a routinized, checklist style of optimised questioning but with some important departures in the patterns of sequence organisation and action-orientation that bear directly on the 'negotiation of what matters'.

\section{Activities and the institutional agenda}

While questions in medical encounters set the agenda for the ongoing talk, patient responses sometimes extend beyond the restrictions imposed by the professional's optimised first position turn. Stivers \& Heritage (2001) suggest that these extended responses are either 
expanded answers, which are nonetheless aligned to the checklist agenda, or narrative expansions, which fully depart from the checklist agenda and are oriented to the patients' 'lifeworld' (Mishler, 1984) concerns. Expanded answers are oriented to difficulties in responding that prompt additional details but still address the agenda of the question, whereas narrative expansions introduce aspects of the patient's own agenda into the interaction (cf. Nishizaka, 2011; Bonnin, 2014). However, both types of extended response may introduce elements of the patients' lifeworld and both are oriented to as accountable, so the distinction is perhaps one of degree rather than discrete categories of response. Our analysis shows that, in the POA, the alignment or otherwise of a patient's response to the agenda of the nurse's question emerges as a collaborative outcome of the interaction between nurse and patient.

Stivers \& Heritage (2001) suggest that narrative expansion displays a progressive transition from formulaic history-taking into interaction that is more conversational in form. Ten Have (1989) discusses a similar mixing of interactional frameworks during GP consultations. However, rather than a transition from one interactional framework to another, he suggests that doctor-patient interaction systematically involves ongoing convergence (Jefferson \& Lee, 1981) between two distinct activities (consultation and troubles-telling). Both Stivers \& Heritage and ten Have thus demonstrate that participants in medical settings shift between the institutional/medical agenda (history-taking/consultation) and the patient's agenda (narrative/troubles-telling). Our own data shows a similar shifting between the checklist agenda of the pre-operative assessment and the patient's agenda, observable in shifts between the type of checklist oriented Q-A sequences described above and troubles telling, but we argue that the distinction emerges as a product of negotiation rather than an a priori property of any particular turn at talk. 


\section{Troubles-telling in Medical Encounters}

'Troubles-talk' refers to a particular kind of extended sequence involving personal disclosure of difficult, intimate or embarrassing episodes or problems (Jefferson, 2015). Crucially, Jefferson \& Lee (1981) argue that it is not the content of the talk per se that makes it a troubles-telling but the projected trajectory of the talk and the locally invoked categories for the participants (e.g. troubles-recipient). This is particularly relevant to our analysis as we focus on patients' extended responses introducing potential health problems. In other words, the content of these responses 'might be pre-classified as a trouble' (p.403) but its actual status is a matter of interactional negotiation.

In other medical settings, troubles-telling has been examined as a central activity of the problem attentive phase of the encounter, leading to diagnosis/treatment (Ruusuvuori, 2005, 2007; ten Have, 1989). Questioning in the POA, however, is not typically problem attentive, nor is diagnosis/treatment relevant, as the focus is on 'fitness for surgery'. Troubles-oriented talk nonetheless occasionally emerges in the context of patients' expanded responses which potentially challenge their fitness for surgery. In these contexts, the nurses observably orient to the institutional goal of probing for and recording potentially relevant information.

In the analysis that follows we demonstrate how routine preoperative sequences normatively orient to an 'optimised' design involving 'no-problem' or minimally expanded answers to checklist questions, but that where responses are expanded and dispreferred, troublesoriented talk may be deployed as a resource for negotiating 'what matters' to this local agenda in the context of the epistemic and institutional asymmetries of this particular setting. 


\section{DATA AND METHODS}

Data from fifteen POAs with six different nurses were audio-recorded from an NHS hospital in Scotland. Ethical permission to audio-record (but not video-record) and transcribe was obtained from the NHS ethics board and informed consent was secured from all participants in advance (via letter). Anonymity for all participants (including third parties) was assured by the alteration of potentially identifying details. The recording equipment was left with the nurses to record their own sessions and they were responsible for confirming consent with patients before the session commenced.

The data are transcribed and analysed using conversation analysis (CA), an approach which studies the sequential patterning of turns at talk to reveal members' understandings of the interaction (Sidnell \& Stivers, 2013).

\section{DATA ANALYSIS}

In what follows we first demonstrate orientation to optimised checklist questioning before considering examples where patients depart from this normative orientation with dispreferred, expanded responses. We then examine the interactional resources deployed by nurses and patients to negotiate the relevance of these expansions to the medical agenda. 
Robinson (2006) demonstrates how the opening sequences of primary care visits index clinicians' understanding of patients' reasons for the visit. Similarly, in POAs, nurses explicitly frame the interaction by referring to institutional goals of form-filling and information-checking, as in Extract 1 (see also Extract 4, 1.1):

\section{Extract 1}

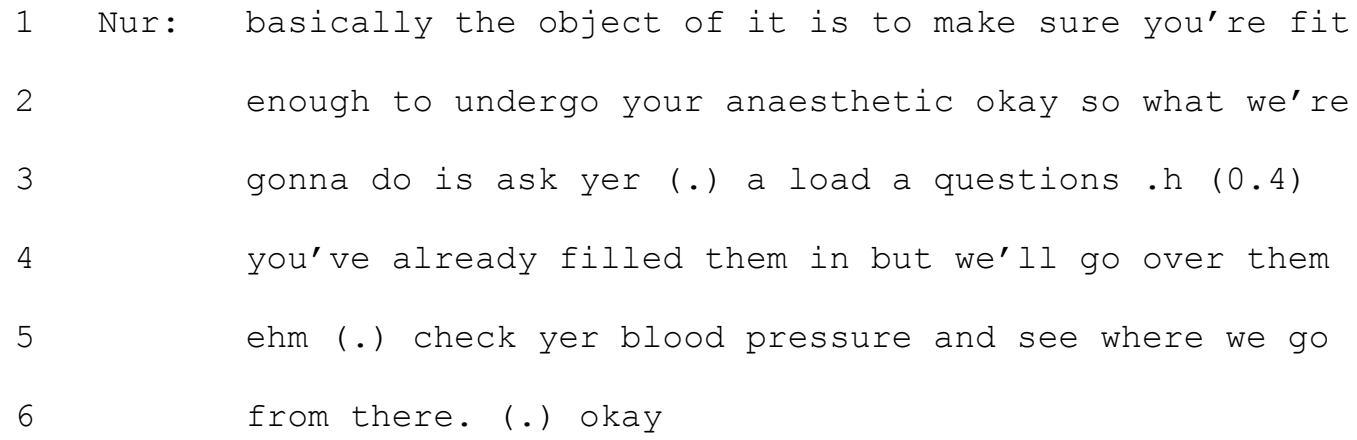

The nurse's orientation to the process as a bureaucratic requirement is displayed through her use of the institutional first person plural subject (Wilson, 1990) and informal, semantically loaded lexical choices ("a load a questions"). Heritage \& Sorjonen (1994) suggest that, rather than undermining patient-centredness, invoking the bureaucratic nature of the task distances it from the nurse and preserves the overarching emphasis on affiliative relationship-building.

The subsequent interaction displays the features of a routine, checklist medical encounter, including minimisation, and-prefacing and optimisation. Extract 2 illustrates minimisation in the design of both the nurse's questions and the patient's response. 


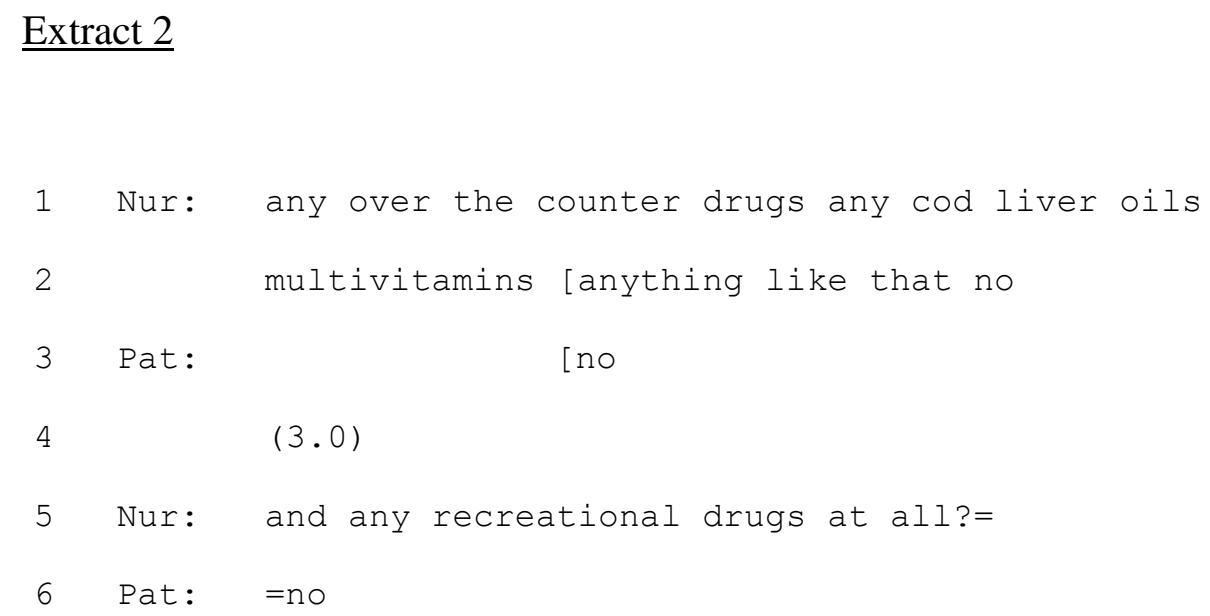

The nurse's questions are grammatically reduced polar interrogatives designed to elicit unelaborated yes/no responses. Line 5 also illustrates and-prefacing, which invokes the agenda-based character of the question and its status as a "routine next" in a series of questions, thereby also treating the preceding response as unproblematic and sufficient (Heritage \& Sorjonen, 1994). In addition, the formulation of the nurse's questions with the indefinite negative polarity item any projects a no response, conforming to the 'no-problem' orientation of the principle of optimisation (Bolinger, 1956; Heritage et al., 2007).

Extract 3 shows the normative force of the principle of optimisation:

\section{$\underline{\text { Extract } 3}$}

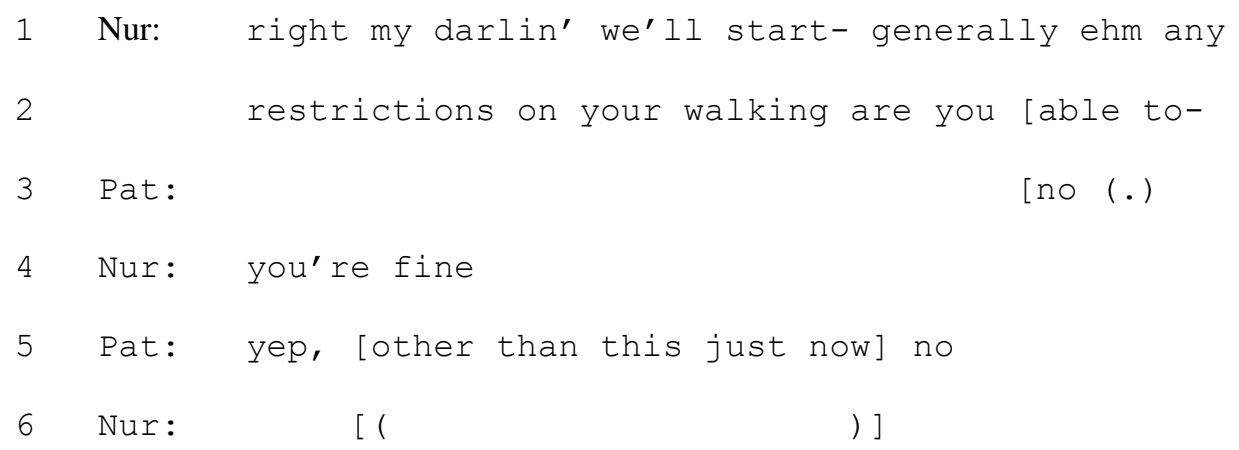


The nurse initially formulates her question with any ("any restrictions") and then moves straight into a reformulation "Are you able to-" in overlap with patient's minimised preferred response "no". The overlapped reformulation is repaired to the declarative question "you're fine" which formulates the upshot of the initial Q-A sequence but switches the polarity of the preferred response. The nurse's incomplete question seems likely to have been aimed at a reformulation providing an optimised alternative question taking into account the patient's presenting problem. The patient expansion may also be oriented to the apparent contradiction between the optimised responses and the reported "this just now" or to the switch in polarity of response occasioned by the nurse's turn design. Crucially, the initial and subsequent formulations are oriented to no-problem outcomes which the patient produces one after the other before qualifying with an expansion (1.5) referring to her current problem with walking. Thus, the patient conforms to the principle of optimisation despite surgery-related problems with walking. In other words, neither participant orients to the POA as problem-attentive.

\section{Departures from 'routine' data gathering}

In the previous examples, the turns of both patients and nurses were oriented to 'routine', minimal, no-problem responses, and the sequence accordingly involved a rapid exchange of turns with little elaboration. Sometimes, however, patients produce dispreferred responses that extend beyond the projected restrictions of the question design. In our data, the nurses' uptake of patients' extended responses shows a mixture of information-oriented or troubles- 
oriented receipts. Information receipts consist of minimal responses (e.g. 'right okay'), repetition and pursuit of expansion through contingent questions (Heritage \& Sorjonen, 1994). Troubles-oriented receipts consist of empathic acknowledgement or assessment of the trouble as trouble (Jefferson, 1984). Our analysis reveals that these different forms of uptake implicitly index the patient's non-minimal response as either an extended answer aligned to the agenda of the question or as a narrative expansion that has moved away from the medical agenda.

\section{Information-oriented uptake}

In the following extract, the patient confirms a slight hearing problem which the nurse follows up with a contingent question about hearing aids (1.5). This contingent question is designed for a yes-no response, but receives a transformative, non-conforming response. Grammatically nonconforming responses index a potential problem with the original question (Raymond, 2003), while transformative answers, resist not just the grammatical design of the question but also the terms or the agenda of the question, and so provide clues to the problems with the direct answer (Stivers \& Hayashi, 2010):

\section{Extract 4}

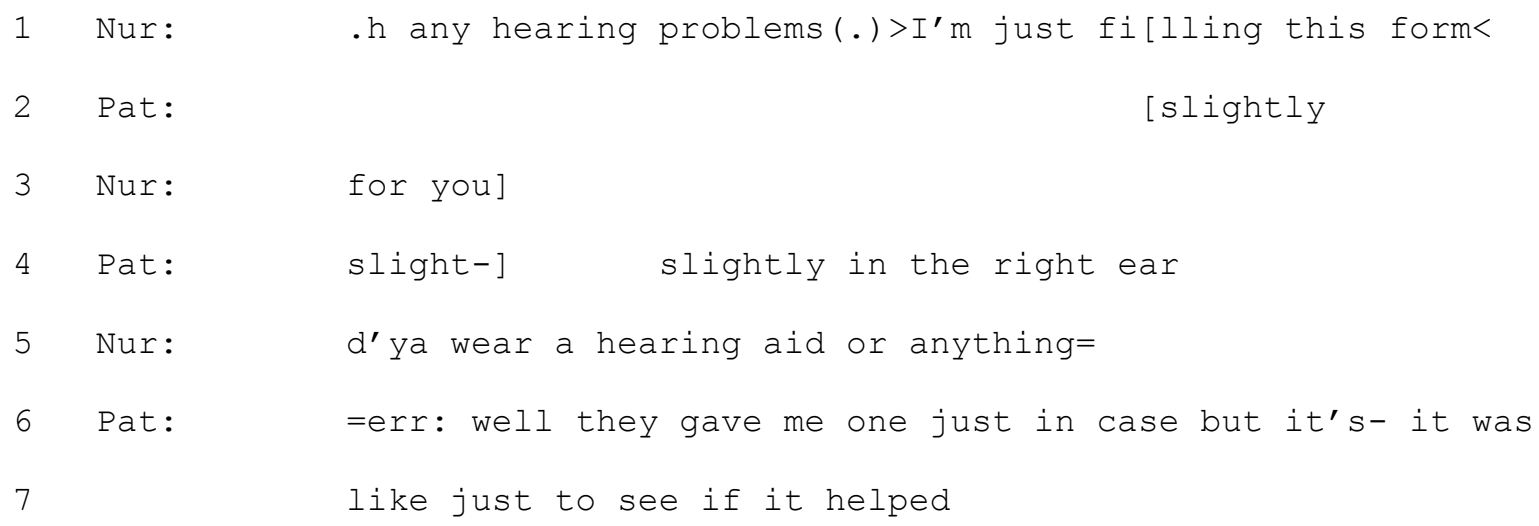




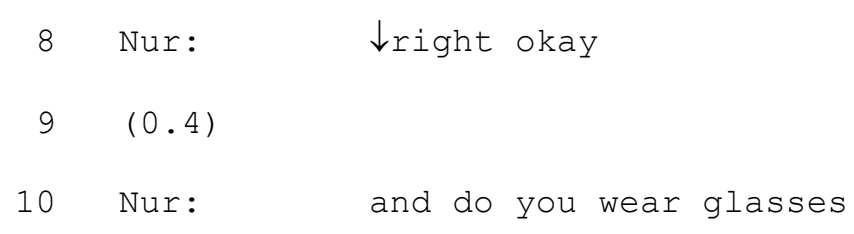

The patient's transformative answer (1.6) is oriented to difficulties with the potential implications of a simple fitted 'no' response. The contingent question is sequentially positioned to be understood as further probing his deafness and its relevance for surgery. Hence a fitted 'yes' or 'no' response would not merely confirm or disconfirm the hearing aid but would be oriented to the agenda of the extended sequence. The transformative response is designed to resist the implications of this agenda.

The important observation for our analysis is that the nurse's uptake (1.8) takes the form of a composite sequence closing third (SCT) (Schegloff, 2007): "right okay". "[R]ight" is a response token that marks epistemic progression and "okay" marks possible closure by claiming acceptance of the preceding second pair part as responsive to the first. In this way, the nurse orients to the information about the hearing aid as having answered the checklist question (presumably having inferred a likely "no" response). On the other hand, the patient's non-conforming response is a dispreferred SPP and these are typically oriented to as expansion relevant. However, through the SCT and the noticeable absence of sequence expansion, the nurse conveys that the requirements of the checklist question have been met and that expansion of the volunteered information is not relevant. In other words, the nurse resolves the patient's struggle with providing a fitted response by marking the sequence as complete; her SCT simultaneously marks receipt of an answer and signals that the additional detail in the patients' response does not 'matter' to the checklist. The patient correspondingly orients to the sequence as closed. In contrast, in the following extract, the nurse's 
information-oriented $3^{\text {rd }}$ position responses are expansion-oriented and elicit further details from the patient.

This extract begins with the nurse's question which has the declarative formatting typical of an optimized question. However, the patient does not respond with the preferred minimal, 'no problem' response for which the question is designed, but offers additional information 'only when I'm running'. This triggers non-minimal post-expansion to elicit further information (a fuller version of this extract is examined in detail later in this paper):

\section{$\underline{\text { Extract } 5}$}

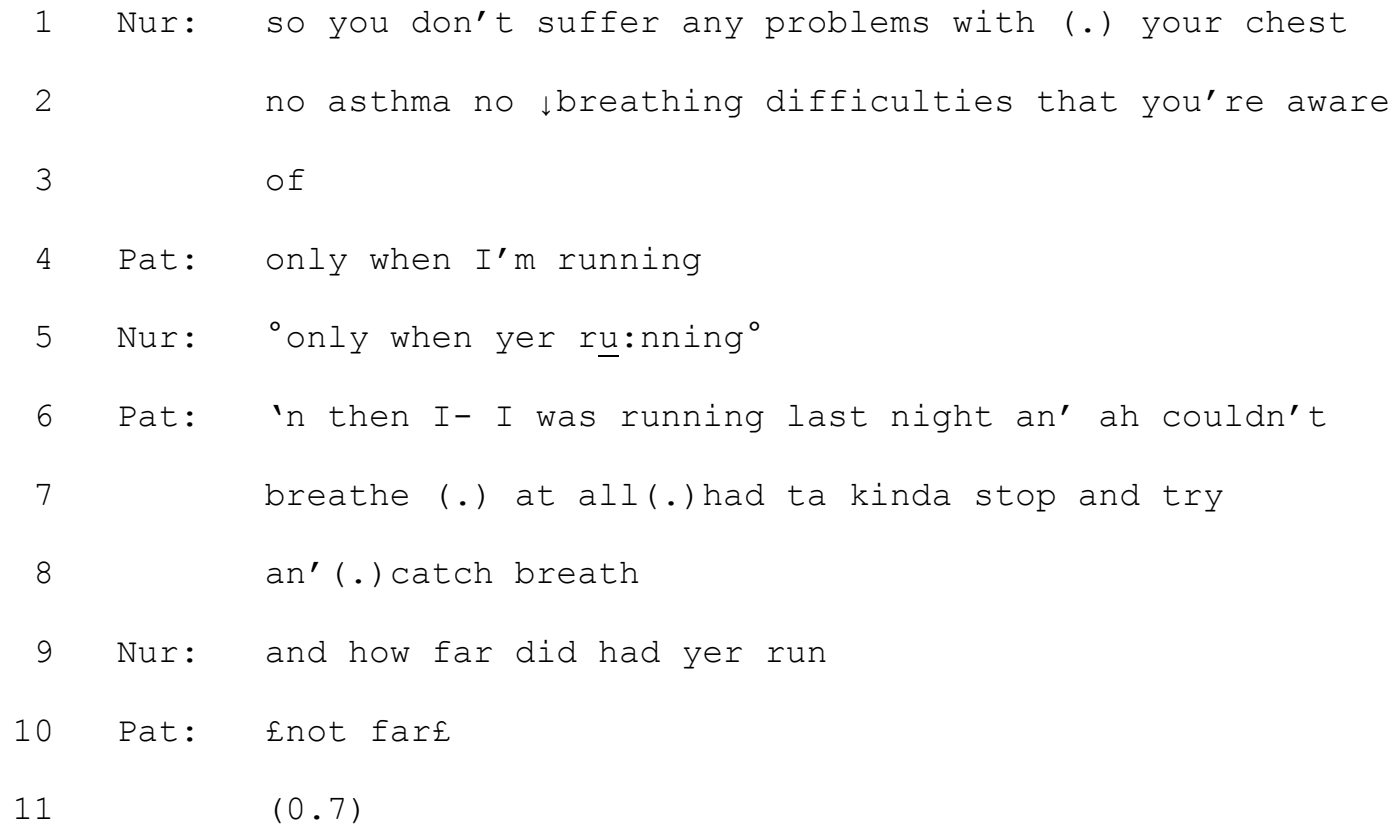

The mixture of preferred and dispreferred features of the patient's response in line 4 point to the patient's struggle to fit her response to both the immediate sequential context and the overarching institutional agenda. Firstly, it is a disaligned response that reports on breathing difficulties so disagrees with the optimized assumption of the nurse's question. In addition, 
similar to extract 4 , it is a transformative, non-conforming response to a yes-no question, so indexes a problem with the question. On the other hand, the response remains clearly within the agenda of the question, suggesting that the problem is with the terms of the question. Moreover, although it is a dispreferred, disaligned response, it is produced in a preferred format and is prefaced with "only" which minimizes the consequences of the disagreement. This suggests that the patient is implying that the breathlessness is not relevant to her operative safety and hence is still oriented to the principle of optimization at the level of the institutional medical agenda (cf. Lee (2011) on transformative answers and orientation to higher level institutional goals).

The nurse's quiet third position repetition (1.5) displays the recordable relevance of the information for the checklist but does not implicate sequence closure and elicits further information from the patient (perhaps oriented to the accountability of the preceding dispreferred second). This begins as an and-prefaced continuation of the generalized account of the patient's breathlessness when running, but then the patient self-repairs and initiates a narrative description of a single incident. The patient's response here is no longer oriented to optimization. Indeed, the narrative potentially constitutes a move away from the agenda of the question. However, it is still topically relevant and the nurse indexes topical coherence by the and-prefaced question in line 9 that ties the implications of the narrative back into the checklist activity and receives a more checklist-conforming unelaborated response from the patient. In this way, the relevance of the patient's responses to the checklist emerges as a negotiated outcome of the patient's talk and the nurse's uptake.

\section{$\underline{\text { Troubles-oriented uptake }}$}


The next extract provides a clear contrast with the information-oriented stance of the nurse in Extracts 4 and 5:

\section{$\underline{\text { Extract } 6}$}

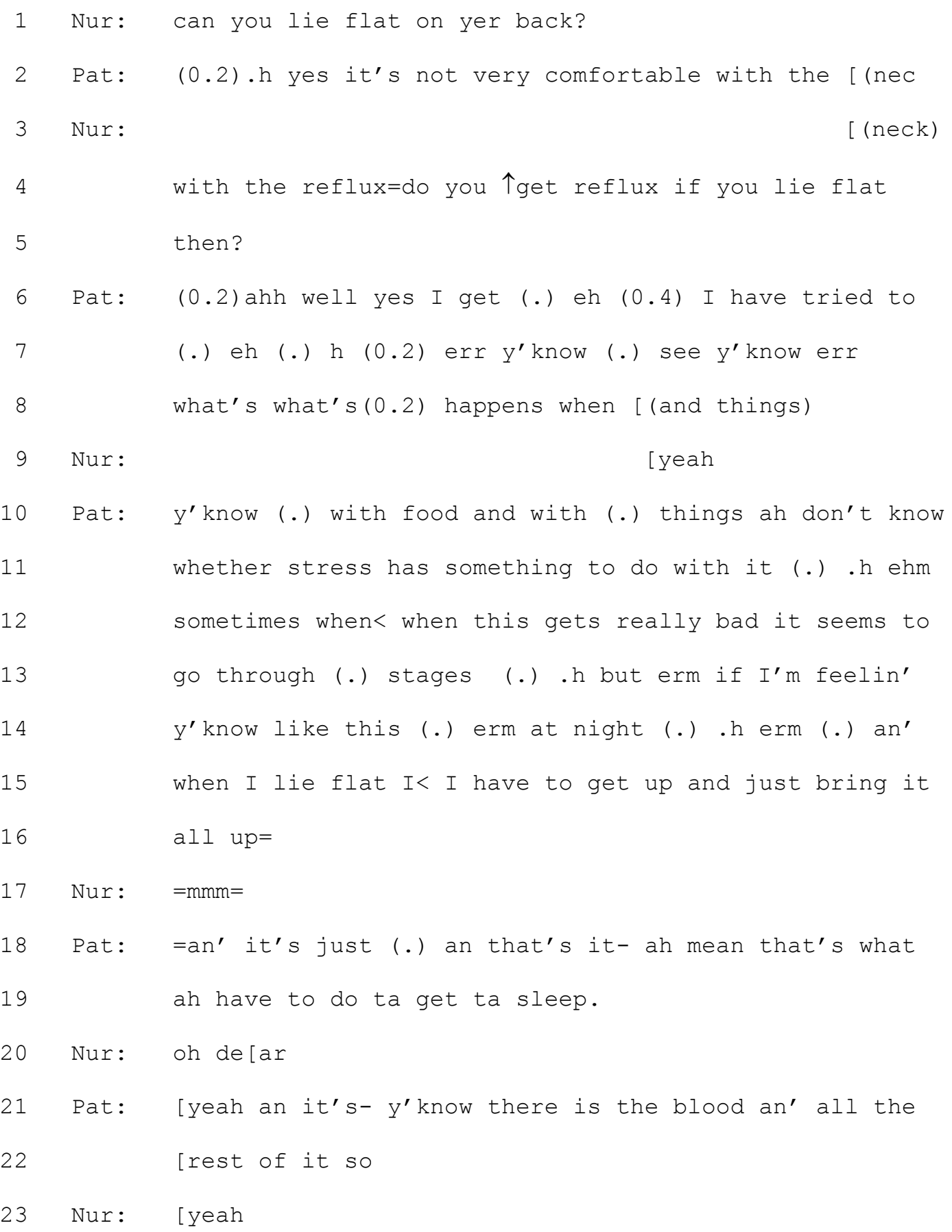




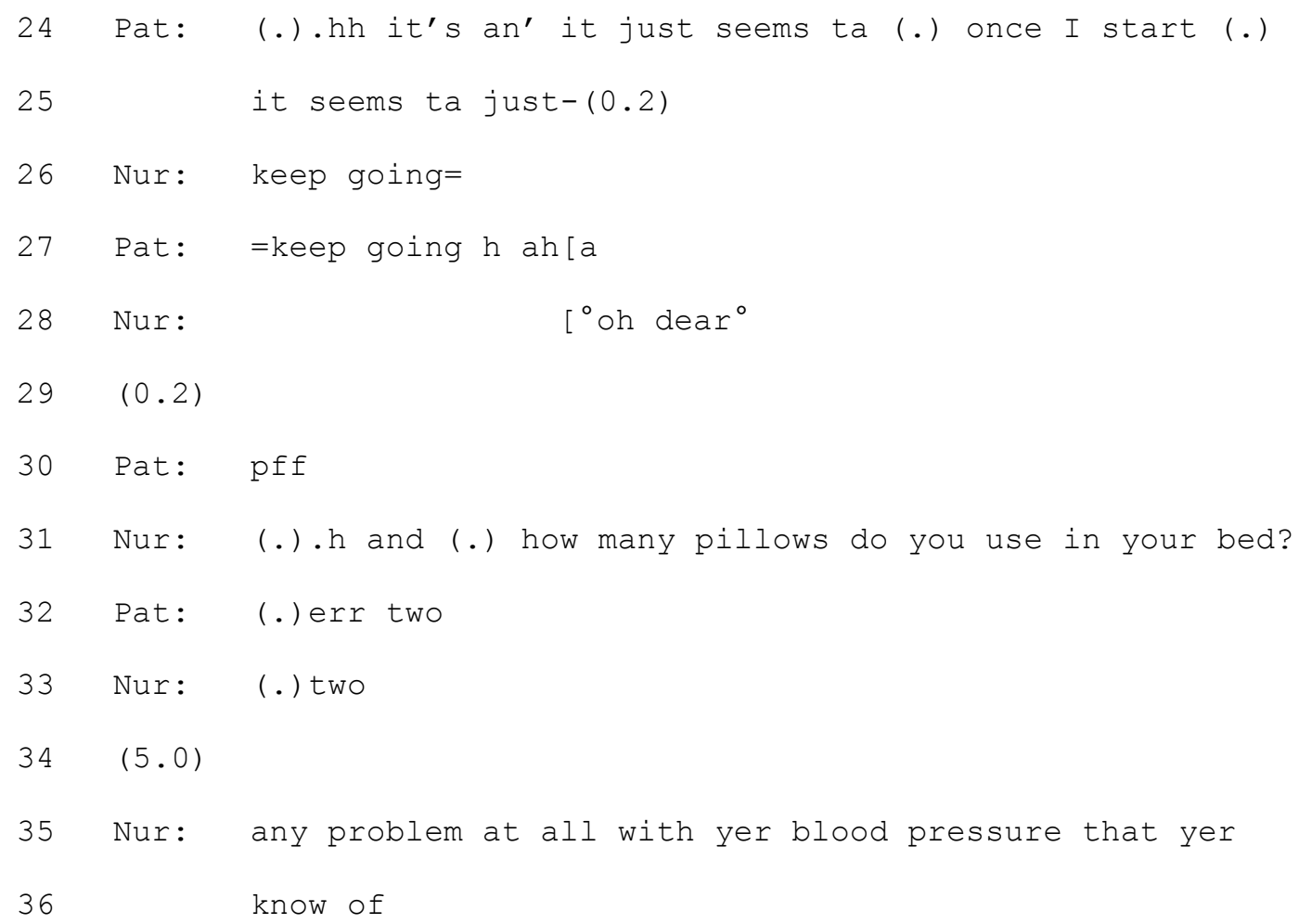

This extract begins with a polar interrogative designed for an optimised yes response. The patient produces the preferred "yes" but prefaced with a short delay that anticipates the less optimal expansion, "it's not very comfortable with the (neck)". This appears to be a reference to the patient's condition as the nurse produces an overlapping reference to the patient's problem with reflux and immediately reformulates her question as an upshot of the patient's ambivalent response. This reformulation (11.4-5) is problem attentive; it does not presuppose a 'no problem' response, and the patient begins an expanded response that is hearably populated with numerous hesitations, restarts and vague formulations, though still oriented to the agenda of the question. On line 13, the patient starts to move to a more experienceoriented narrative, prefaced with sometimes, but the narrative is still designed to display orientation to the agenda of the question through overt reference to its original wording "when I lie flat" (1.15). At the conclusion of the patient's narrative, the nurse offers an affiliative and sympathetic acknowledgement of the patient's talk as troubles-talk, "oh dear" 
(1.20), invoking their own status as a troubles-recipient. In this way, the nurse orients to the narrative as a troubles-telling rather than as informative for the POA. The patient follows this first 'oh dear', with a responsive 'yeah' that responds to and overlaps with the nurse's "oh dear" and then a continuation which offers more 'doctorable' features of the condition (1.21: “blood an' all”) (Heritage and Robinson, 2006: 57). The nurse however responds with a collaborative completion of the patient's turn "keep going" (1.27) and a second "oh dear", thus still orienting to the patient's description as a troubles-telling. The troubles-oriented sequence is then concluded as the nurse returns to the medical agenda with a related but new 'and-prefaced' question about the number of pillows used by the patient. The nurse's minimal troubles-oriented responses thus convey that the details offered by the patient are not relevant to the immediate medical agenda and so provide a resource for negotiating relevance whilst crucially maintaining empathy.

This analysis shows that the 'business at hand' involves information that is sometimes troubles-oriented but is not, in the first instance at least, sequentially produced as a troublestelling. This is particularly relevant in problem attentive medical questioning such as is seen in lines 4-5. The nurse's question about reflux elicits troubles implicative information but as argued by Jefferson and discussed above, it is not the content but the sequential organisation and forms of uptake that mark talk as a troubles-telling. Troubles-telling as an activity is thus invoked by the participants at certain points in the interaction. At these points, participants observably negotiate the institutional/social relevance of the troubles-related talk and the categorial roles and identities implicated therein. In particular, the recognisability of the elements of a troubles-telling sequence appears to provide the participants with a strongly affiliative resource for disengaging from the institutional task of information-gathering. 
Jefferson (1988) describes the trajectory of troubles-telling in three stages: announcement; exposition; affiliation response. Each stage involves a stepping up of 'interactional intimacy' collaboratively negotiated by troubles-teller and troubles-recipient. An initial troublesoriented uptake of an announcement commits the recipient to the locally accomplished status of troubles-recipient and elicits exposition of the trouble. This in turn receives heightened affiliation by the recipient that elicits further expansion of the troubles-report. It is this further expansion, the affiliation response, that is the 'topical and relational heart of troubles-telling' (p. 43) and it emerges as a response to the increased level of empathy/affiliation in the uptake of the exposition relative to the uptake of the initial announcement.

In our data, troubles-telling is invoked when the nurse orients to a patient response with a display of troubles-recipiency. Thus, in extract 6 , as the patient moves away from the medical agenda, the nurses' responses overtly orient to the patients' talk as a troubles-telling through a display of empathic acknowledgement ("oh dear"). In this way, the nurse orients to the patient's talk as a troubles-announcement and elicits exposition of the trouble (1.21). In other words, the initial troubles-oriented uptake by the nurse (line 20) provides the patient with the 'go-ahead' to expand their response while also marking it as moving away from the medical agenda.

In so doing, the nurse invokes a shift from her institutional role as nurse to a locally accomplished identity as troubles-recipient. Crucially, the nurse's troubles-oriented uptake addresses that part of the patient's response which is affect-oriented rather than receipting the response as information relevant to the history taking. Interestingly, following the nurse's 
initial move to troubles-recipiency, the patient appears to attempt to realign their talk with the information-oriented medical agenda through the repair in line 21 that shifts focus from the experiential to the physical/doctorable ("blood an' all that"). However, the nurse does not correspondingly revert to information-oriented uptake but responds to the patient's on-going narrative with a continuer (1.23), an affiliative co-completion (1.26) and finally a second "oh dear" (1.28) which receipts the narrative as a troubles-exposition. In this way, the nurse and patient tease apart information and affect and collaboratively negotiate that the move to troubles-recipiency marks official absence of uptake of the medical/‘doctorable’ information.

However, invoking troubles-recipiency also brings a new and equally delicate task of exiting from the troubles-talk to return to the checklist without appearing to disregard the patient's concerns. Exiting from troubles talk in other medical settings, e.g. primary care, may be accomplished via institutionally mandated activities such as advice giving or diagnosis and remedy (Ruusuvuori, 2005, 2007). However, such activities are not relevant in the POA which is solely oriented to information gathering. In contrast to the ideal schema that Jefferson describes, the nurses in our data use the same response form for the uptake of both announcement and exposition. In other words, the increase in empathy that Jefferson observed to mark the shift from troubles-recipiency to affiliation is noticeably absent in the nurse's responses. Moreover, the patients orient to this noticeable absence of heightened affiliation as closure implicative. In other words, while the first troubles-receipt invites elaboration of the trouble, the repeated receipt format appears to block the move to 'affiliation response'. Instead the patient (1.30) produces just the very minimal “pff” leaving the nurse free to move the "relevant next" in the medical questioning, a question about pillows. 
Whilst the noticeable absence of increased affiliation in the uptake of the exposition of a troubles-telling risks being interpreted as a lack of empathy, or as a 'synthetic', professionally mandated empathy, the nurse combines the repetition with a highly local, recipient-designed display of empathy/ intersubjective understanding: the collaborative completion, "keep going” (1.27). In this way, the nurse sensitively accomplishes what might otherwise be seen as a premature exiting from the troubles-telling sequence.

It is striking to note that it is not merely the practice of responding with a troubles-oriented uptake that recurs here and elsewhere in our data but rather the full sequential trajectory:

A. Pat: extended response

B. Nur: troubles-oriented uptake

C. Pat: troubles exposition (with reference to doctorability)

D. Nur: repeated troubles-oriented uptake (combined with local, recipientdesigned display of shared understanding)

For example, in the following extract (analysed in Benwell \& McCreaddie, 2016), the nurse repeats the troubles-oriented response "what a shame" (1.7 \& 1.10) but also displays shared understanding of the patient's central concern through repetition of "young", while the patient following the initial troubles-oriented uptake focuses on the doctorable "strokes" and seizures" in the troubles exposition:

\section{Extract 7}

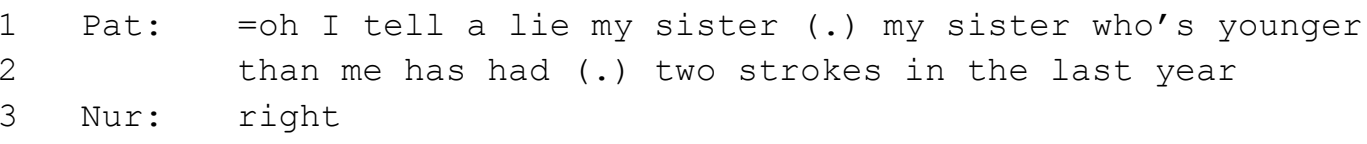




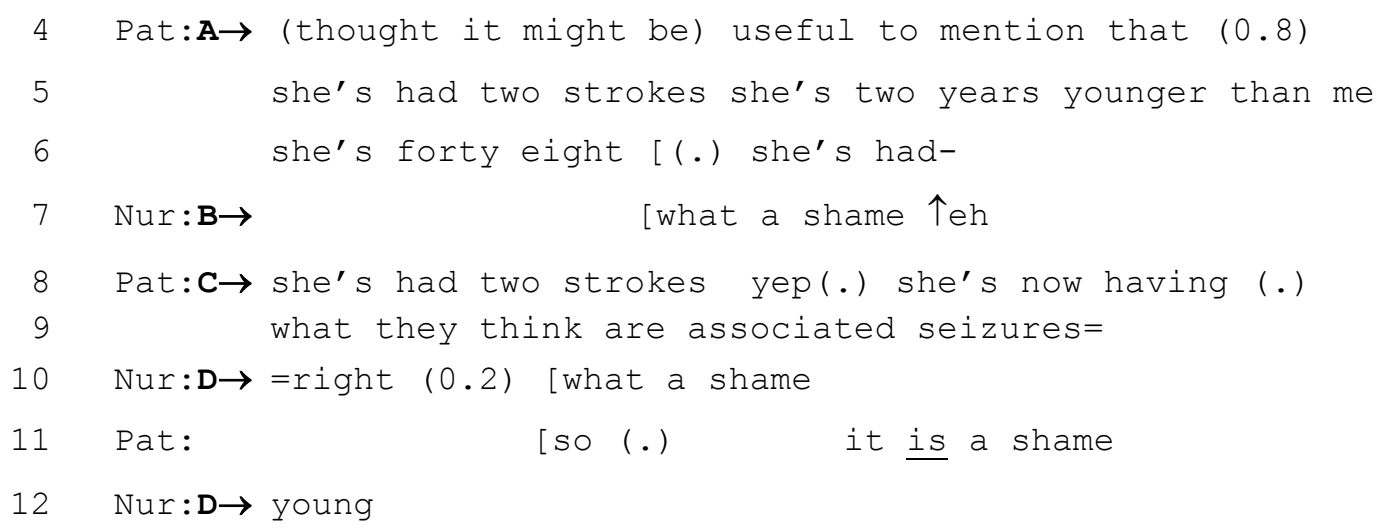

Examining our data in light of the detailed stages of Jefferson's candidate troubles-telling sequence thus shows how invoking troubles-telling (B) provides both interactional space for the patient to articulate their concerns (C) but also the resources to exit from the troublesoriented talk without moving into a full-blown troubles-telling sequence (D). Note that the observation that patients sometimes resist the troubles-telling frame by including overt reference to "doctorable" aspects of their complaint (e.g. Ex.6, 1.21) provides participant orientation evidence of the shared understanding of the implications of invoking troublestelling in these contexts.

On the other hand, closer examination of an expanded version of Extract 5, (given here as Extract 8), suggests that troubles-talk also provides the patient with interactional resources to resist the checklist agenda (cf. Pilnick and Coleman, 2006). As noted above, this sequence begins with a transformative, non-optimal response to the nurse's question about breathing difficulties. This triggers an extended series of information-oriented, contingent questions by the nurse $(11.9,13,26)$ before arriving at the nurse's no-problem summary (11.34-36):

\section{$\underline{\text { Extract } 8}$}




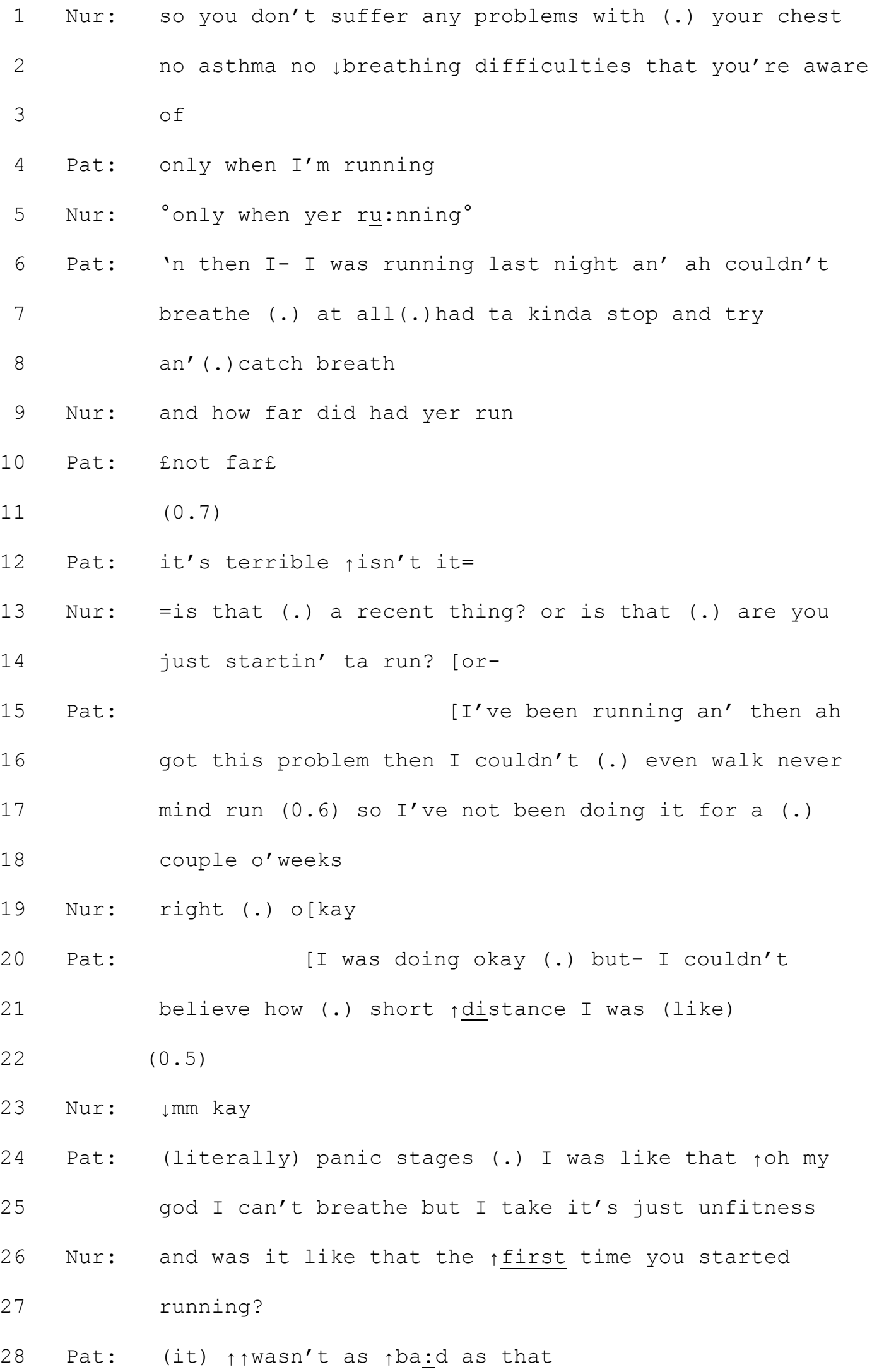




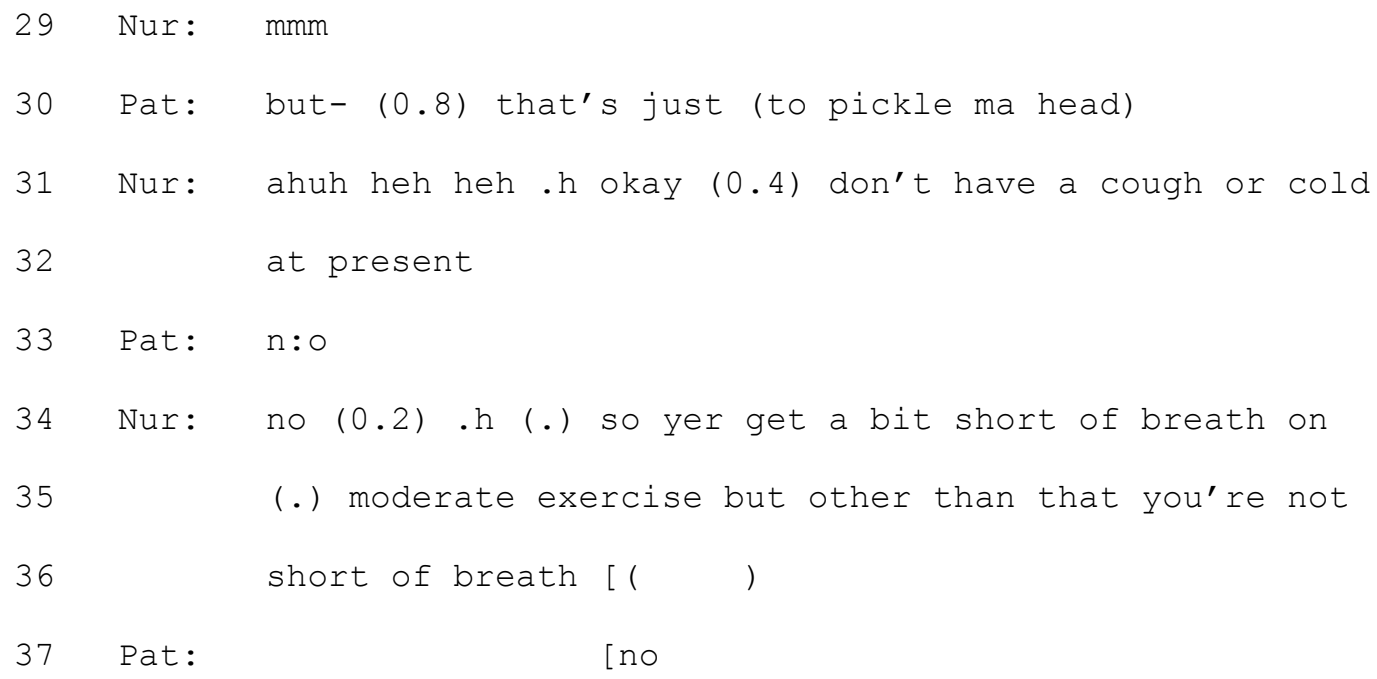

The overall trajectory of the sequence is thus oriented to information gathering and the nurse consistently remains within the interactional framework of the checklist agenda, producing either information receipts or contingent questions. However, the patient's expanded responses move between information-oriented reporting and troubles-oriented narrative. Ten Have (1989) suggests that troubles-telling 'dramatizes the suffering and emotionally involves the teller'. Here, the patient's responses repeatedly display a shift away from the generic temporal reference and information checking of the questions and into more conversational formats involving dramatic combinations of reported thought and extreme case formulations focused on the subjective, situated experience of the patient.

In lines 6-8, the patient begins with an and-prefaced continuation of the generalized account of her breathlessness, but then self-repairs and initiates a troubles-oriented narrative description of a single incident in which the problems of breathlessness are produced with an Extreme Case Formulation (ECF) (Pomerantz, 1986) (1.6-7: “couldn't breathe at all”). The nurse responds with an information-oriented contingent question which receives a minimal information-oriented response by the patient who then moves away again from the checklist 
agenda, producing a negatively dramatizing assessment (1.12). This realigns the patient's talk with the troubles-talk in lines 6-8 but might also be interpreted as closure implicative, i.e. as an attempt by the patient to close down further probing of her breathlessness as relevant to the POA. (Note, our analysis is hampered here by the lack of video as it is not clear whether the nurse is writing on the form at this point. Ten Have (1989) suggests that troubles-talk occurs in gaps in medical talk where the professional is occupied with other tasks.) The nurse, however, does not respond to the assessment in line 12 and proceeds with informationoriented questioning about the patient's running. The patient complies, providing further information $(1.15$ - 18) before moving again into narrative expansion with descriptions of reported thought ("I couldn't believe how short distance", "I was like that oh my god I can't breathe") and ECFs ("literally panic stations" "can't breathe").

The suggestion that these troubles-oriented narratives about a specific running experience work up a display of potential non-relevance by the patient is further foregrounded by the patient's assessment, “but I take it's just unfitness" (1.25), which invokes a contrast between fitness issues and medically relevant issues. The minimiser adverb "just" indicates that there is nothing more to say, so is also hearable as closure-implicative (Drew, 1992; Lee \& Sheon, 2008). The nurse again does not respond to the assessment but produces a further checklistoriented, and-prefaced question which again receives an informative response (1.28) and another hearably closure-implicative assessment with "just", to which the nurse responds with laughter and an aligned move to close both the topic of running (1.31) and the checklist item about breathlessness (11.34-36). 
There are several interesting recurring features in this sequence. Firstly, the sequence cycles through a recurring pattern in which the patient moves from a report of a potential trouble that is fitted to the checklist agenda to a more conversational narrative that orients to the trouble as relevant to the patient's 'lifeworld' concerns with fitness (Mishler, 1984) before producing a bid for closure. In other words, the patient appears to bring into focus their lifeworld concerns with the impact of their health problem on their fitness and simultaneously display resistance to the immediate medical relevance of those concerns for the POA (cf. Denvir (2012) on the normal/healthy stance enacted by patients in response to substance use history taking). The nurse's uptake on the other hand consistently orients to the informational relevance of the patient's responses for the checklist. This elicits further talk from the patient showing that the nurse's information-oriented uptake is treated by the patient as expansionrelevant. Thus the negotiation of relevance emerges as a collaborative outcome of the patient's troubles-related talk and the nurse's uptake. Moreover the sequential working out of the tension between information-orientation and troubles-orientation evident in this extract indexes the complex layers of epistemic and institutional asymmetry tied to this institutional setting (Sidnell, 2012).

\section{Invoking troubles-telling in patient responses}

While the distinction between information-orientation and troubles-orientation is unambiguous in nurses' uptake of patients' responses, the distinction between reporting on potential problems (in line with the checklist) and invoking troubles-telling (moving away from the checklist) in patients' talk is less straightforward. A dispreferred SPP to a checklist question inherently introduces what ten Have (1989) calls a 'report about a self-experienced trouble' but such reports can be, and are, produced without invoking troubles-telling. For 
example, the initial report of breathlessness in Extract 8 does not invoke troubles-telling. A report about a potential trouble is argued to become recognisably a troubles-telling when it involves a shift in focus from the trouble to the person (Jefferson, 1980). However, the boundary between focus on the trouble and focus on the person is not always clear. Ten Have (1989) also suggests that troubles-telling is invoked when patients provide more information than is strictly necessary for the medical encounter. Our contention, however, is that ten Have's assessment, 'more information than strictly necessary', is not made from the patient's perspective. Our analysis indicates that patients are typically oriented to providing a response within the agenda of the question (e.g. Ex6, 1.15) but that non-minimal responses and SPP increments index difficulty with providing a fitted response. The data also showed that potentially troubles-oriented responses do not inherently invoke a shift to the activity of troubles-telling.

By contrast, in Extract 8, the patient's SPP increments deploy a range of marked features such as narrative formatting, ECFs and reported thought which offer 'exceptional affordances for empathic alignment' (Heritage, 2011 p. 177) and clearly shift the focus from the trouble to the patient as experiencer of the trouble, invoking a local identity of troubles-teller. Our analysis shows that these overtly troubles-telling elements provide the patient with resources to resist the medical relevance of her concerns. In other words, as with the nurses' troublesoriented uptake, the patients' more overt shift to troubles-telling marks a shift away from the checklist agenda, as evidenced by the patient's invoked contrast between medical relevance and "just unfitness" (1.25).

\section{CONCLUSION}


The POA is a crucial stage of the perioperative process designed to reassure patients and identify potential areas of risk. Putting the patient at ease and providing interactional space for patients to raise health concerns is vital. Our data provided significant evidence that patients sometimes present health information in dispreferred expanded responses whose relevance to the checklist must be collaboratively negotiated.

Nurses orient to these potential reports of trouble either as information pertaining to the checklist, or as a troubles-telling for which an expression of sympathy is relevant. The locally achieved contrast between these two types of response, however, is about medical relevance rather than the choice between information-recording versus empathy. Both types of response provide patient-centred resources for curtailing elaboration of unnecessary detail. In extract 4, the nurse's SCT acknowledges the patient's response as relevant and sufficient despite unresolved details in the patient's turn. In extract 6, troubles-oriented uptake of the patient's talk ("oh dear") provides the interactional space for the patient to express their concerns whilst also signalling that the concerns are not surgically relevant. Moreover, the absence of the 'heightened' affiliation that might prompt further disclosure suggests that the nurses are resisting the escalation of such sequences, and reorienting the interaction back to the medical agenda in a way that is nonetheless sensitive and preserves the patients' sense that their concerns are being accommodated.

In extract 8 (also 5), the patient's introduction of troubles-relevant information about her health and lifestyle are notably oriented to by the nurse as potentially medically relevant, but this trajectory is resisted by the patient who develops it as a distinctly troubles-telling 
sequence, partially, we argue, to resist the checklist agenda itself. The tension that arises between two agendas here is particularly fascinating. On the one hand, the patient deploys troubles-telling as a resource to downplay the medical relevance of her breathlessness, whilst simultaneously prioritising her concern with the lifeworld consequences of her presenting problem. On the other hand, the nurse consistently pursues the potential medical relevance of the breathlessness, presumably due to its possible implication for risk associated with surgery.

Troubles-relevant talk by patients has been observed in other studies of healthcare interaction (ten Have, 1989; Stivers and Heritage, 2001; Ruusuvuori, 2005) and the positive benefits accrued when patients' lifeworld concerns bleed into their medical encounters have been noted (Stivers and Heritage, 2001:158; Robinson and Heritage, 2005: 279; Robinson et al, 2015: 719). By providing troubles-oriented responses to patient disclosures, the nurses in our study conform to this patient-centred ethic and create an affiliative interactional space for patients to express their concerns. However, the evidence from our own data also suggests that troubles-talk is largely prompted where patients struggle to provide a fitted response to information-seeking questions. Nurses engaged in POA information gathering have a potentially tricky path to steer between adhering to the checklist in a time-efficient way, and listening to potential concerns open-mindedly and with empathy. The pursuit of the patient's expanded responses in extract 8 shows that at times nurses depart from an orientation to optimised responses where they feel that such information may reveal clues to medicallyrelevant concerns. The deployment of troubles-oriented sympathy tokens, on the other hand, are a sensitive and empathic means of signalling digression from the checklist agenda and reorienting the talk accordingly. 
Our study provides insight into areas worth highlighting for practitioners engaged in preoperative assessments. A patient-centred approach should allow space for patients to reveal potentially relevant health information, which arguably the optimised design of checklist questions may militate against. The analysis shows how patients sometimes struggle to respond within the constraints imposed by checklist questions and highlights the sensitive means by which patients are afforded space to articulate their concerns whilst non-relevant concerns are curtailed and reoriented. The evidence from the interactions analysed here shows that nurses, in our study at least, are already adept and well-practised in these strategies, and that insights from their talk could inform best practice elsewhere.

\section{References}

Abraham, J. (2013) 'Literature review critically exploring and evaluating advanced perioperative roles in United Kingdom (UK)' Journal of Health and Social Care Improvement. 1:1-11.

Benwell, B. \& McCreaddie, M. (2016) Keeping "Small Talk” Small in Health-Care Encounters: Negotiating the Boundaries Between On- and Off-Task Talk. Research on Language and Social Interaction 49(3): 258-271

Bonnin, Juan Eduardo. (2014) Expanded answers to bureaucratic questions: Negotiating access to public healthcare. Journal of Sociolinguistics 18(5): 685-707 
Bolinger, Dwight (1957) Interrogative Structures of American English. Alabama: University of Alabama Press.

Boyd, E. \& Heritage, J. (2006) Taking the history: questioning during comprehensive history-taking. In J. Heritage \& D. Maynard (eds.) Communication in medical care: Interactions between primary care physicians and patients. Cambridge: Cambridge University Press, pp. 151-184.

Bramhall, J (2002) The role of nurses in preoperative assessment. Nursing Times 98(40): 34

Carr, E., Brockbank, K., Allen, S. \& Strike, P. (2006) Patterns and frequency of anxiety in women undergoing gynaecological surgery. Journal of Clinical Nursing 15: 341352.

Chan, Zenobia, Kan, Carmen, Lee, Patrick, Chan, Isabel and Lam, Joyce (2011) A systematic review of qualitative studies: patients' experiences of preoperative communication. Journal of Clinical Nursing 21: 812-824.

Denvir, Paul M. (2012) When patients portray their conduct as normal and healthy: An interactional challenge for thorough substance use history taking. Social Science \& Medicine 75(9): 1650-1659 
Drew, Paul (1992) Contested evidence in courtroom cross-examination: The case of a trial for rape. In Paul Drew, \& John Heritage (Eds.) Talk at work: interaction in institutional settings, Cambridge, Cambridge University Press, pp. 470-520.

Findlay, G.P., Goodwin, A.P.L., Protopapa, K., Smith, N.C.E. \& Mason, M. (2011) Knowing the risk: A review of the perioperative care of surgical patients. A report by the National Confidential Enquiry into Patient Outcome and Death.

Gardner, Rod (2007) The right connections: Acknowledging epistemic progression in talk. Language in Society, 36(3): 319-341.

Gilmartin, J. \& Wright, K. (2008) Day surgery: patients felt abandoned during the preoperative wait. Journal of Clinical Nursing 17: 2418-2425.

Have, P. ten (1989) The consultation as a genre, in: B. Torode (Ed.), Text and Talk as Social Practice: $115-35$, Dordrecht, Foris Publications

Hepburn, A. (2004) Crying: Notes on description, transcription and interaction. Research on Language and Social Interaction, 37, 251-290.

Heritage, J. (2002) Ad hoc inquiries: Two preferences in the design of 'routine' questions in an open context. In Douglas Maynard, Hanneka Houtkoup-Steenstra, Nora K. Schaeffer, \& Hans van der Zouwen. (Eds) Standardisation and Tacit Knowledge: 
Interaction and Practice in the Survey Interview. New York, Wiley Interscience, 31333.

Heritage, J. (2010) Questioning in medicine. In Freed, A. F. \& Ehrlich, S. (eds), Why do you ask?: The function of questions in institutional discourse. Oxford, Oxford University Press, $42-68$.

Heritage, J. (2011) Territories of knowledge, territories of experience: empathic moments in interaction. In Tanya Stivers, Lorenza Mondada and Jakob Steensig (Eds.) 2011. The Morality of Knowledge in Conversation. Cambridge: Cambridge University Press, 159-183.

Heritage, J. and Robinson, J. (2006) 'Accounting for the visit: giving reasons for seeking medical care', in J.Heritage and D.Maynard (eds), Communication in Medical Care: Interactions between Primary Care Physicians and Patients. Cambridge: Cambridge University Press: 48-85.

Heritage, John, Robinson, Jeffrey, Elliott, Marc, Beckett, Megan and Michael Wilkes (2007) Reducing patients' unmet concerns in primary care: the difference one word can make.' Journal of General Internal Medicine 22(10): 1429-1433.

Heritage, J. \& Sorjonen, M. (1994) Constituting and maintaining activities across sequences: and-prefacing as a feature of question design. Language in Society, 23,1-29. 
Heritage, John, \& Sefi, Sue (1992). Dilemmas of advice: Aspects of the delivery and reception of advice in interactions between health visitors and first time mothers. In Paul Drew \& John Heritage (Eds.) Talk at work: interaction in institutional settings. Cambridge: Cambridge University Press, 358-417.

Hines, Sonia, Munday, Judy \& Kynoch, Kate (2013) JBI Database of Systematic Reviews and Implementation Reports 11(9) 73-83.

Jefferson, G. (2015) Talking about Troubles in Conversation. Edited by P. Drew, J. Heritage, G. Lerner and A. Pomerantz. Oxford: Oxford University Press.

Jefferson, G. (1988) On the sequential organization of troubles talk in ordinary conversation. Social Problems, 35(4), 418-442.

Jefferson, G. (1984) 'On the organization of laughter in talk about troubles'. In J.M.Atkinson, and J. Heritage (eds) Structures of Social Action. Cambridge: Cambridge University Press, pp. 346-369.

Jefferson, G. \& Lee, J.R.E. (1981) The rejection of advice: Managing the problematic convergence of a 'troubles-telling' and a 'service encounter'. Journal of Pragmatics $5,399-422$.

Jefferson, Gail (1980) On 'trouble-premonitory' response to inquiry. Sociological Inquiry, $50(3 / 4), 153-185$. 
Jones, A. (2007) Admitting hospital patients: A qualitative study of an everyday nursing task. Nursing Inquiry 14(3):212-23.

Lee, S.-H. (2011). Responding at a higher level: Activity progressivity in calls for service. Journal of Pragmatics, 43, 904-917

Lee, S.H. \& Sheon, N. (2008) Responsibility and risk: accounts of reasons for seeking an HIV test. Sociology of Health and Illness 30(2): 167-81

Lingard, Lorelei, Regehr, Glenn, Orser, Beverley, Reznick, Richard, Baker, Ross, Doran, Diane, Espin, Sherry, Bohnen, John \& Whyte, Sarah (2008) Evaluation of a preoperative checklist and team briefing among surgeons, nurses and anaesthesiologists to reduce failures in communication Arch Surg. 143(1): 12-17.

Malley, Ann, Kenner, Carole, Kim, Tiffany, Blakeney, Barbara (2015) The Role of the Nurse and the Preoperative Assessment in Patient Transitions AORN Journal 102(2) 181 e.1-9.

Mishler, E. (1984) The Discourse of Medicine: Dialectics of Medical Interviews. Norwood, NJ: Ablex.

Mottram, A (2009) Therapeutic relationships in day surgery: a grounded theory study. Journal of Clinical Nursing 18: 2830-2837. 
Nishizaka, Aug. (2011) Response expansion as a practice for raising a concern during regular prenatal checkups. Communication \& Medicine 8: 247-259

Pilnick, Alison and Coleman, Tim (2006) Death, depression and 'defensive expansion': Closing down smoking as an issue for discussion in GP consultations Social Science \& Medicine, 62(10):2500-2512

Pomerantz, A. (1986) Extreme Case Formulations: A way of legitimizing claims'. Human Studies 9(2/3): 219-229.

Raymond, Geoffrey (2003) Grammar and social organisation: yes/no interrogatives and the structure of responding. American Sociological Review 68:939-67.

Raymond, Geoffrey (2010) Grammar and social relations: Alternative forms of yes/no initiating actions in health visitor interactions. In Alice, F. Freed \& Susan Ehrlich (eds), "Why do you ask?”: The function of questions in institutional discourse. Oxford, Oxford University Press, 87-107.

Robinson, Jeffrey (2006) Soliciting patients' presenting concerns. In John Heritage \& Douglas Maynard (eds), Communication in Medical Care: Interactions between Primary Care Physicians and Patients, New York, Cambridge University Press, 2247. 
Robinson, Jeffrey and Heritage, John (2005) The structure of patients' presenting concerns: the completion relevance of current symptoms. Social Science and Medicine 61(2): 481-93.

Robinson, Jeffrey D., Tate, Alexandra and Heritage, John (2016) Agenda setting revisited: When and how do primary care physicians solicit patients' additional concerns? Patient Education and Counselling 99(5) 718-723.

Roter, Debra \& Hall, Judith (2006) Doctors Talking with Patients/Patients Talking with Doctor: Improving Communication in Medical Visits, Westport, Conn.: Praeger.

Ruusuvuori, J. (2005) Empathy and sympathy in action: Attending to patients' troubles in Finnish homeopathic and GP consultations. Social Psychology Quarterly, 68, 204 222.

Ruusuvuori, J. (2007) Managing affect: integration of empathy and problem-solving in health encounters. Discourse Studies, 9 (5), 597-622.

Schegloff, E. A. (2007) Sequence organization in Interaction: A Primer in Conversation Analysis (Vol. 1). Cambridge, England: Cambridge University Press.

Sidnell, J. (2012) Declaratives, questioning, defeasibility. Research on Language and Social Interaction 45(1), 53-60. 
Sidnell, J. \& Stivers, T. (2013) The Handbook of Conversation Analysis Oxford, Wiley Blackwell

Stivers, T. (2007) Prescribing under Pressure: Parent-physician Conversations and Antibiotics. New York, Oxford University Press.

Stivers, Tanya and Makoto Hayashi. 2010. Transformative answers: One way to resist a question's constraints. Language in Society 39: 1-25.

Stivers, T. \& Heritage, J. (2001) Breaking the sequential mold: answering 'more than the question' during comprehensive history taking. Text 2001, 21: 151-185.

Stivers, T. \& Majid, A. (2007) Questioning children. Interactional Evidence of Implicit Bias in Medical Interviews. Social Psychology Quarterly 70, 424-41.

Wilson, J. (1990) Politically Speaking Oxford, Blackwell 


\title{
Negotiating relevance in pre-operative assessments
}

\begin{abstract}
Preoperative assessments provide an essential clinical risk assessment aimed at identifying patient risks and requirements prior to surgery. As such they require effective and sensitive information-gathering skills. In addition to physical examination, the preoperative assessment includes a series of routine questions assessing a patient's fitness for surgery. These questions are typically designed to elicit minimal, 'no problem' responses, but patients sometimes produce expanded responses that extend beyond the projected information. Our analysis reveals that troubles-telling is often invoked by both nurses and patients as an effective, patient-centred resource for negotiating the medical relevance of patients' concerns in these contexts.
\end{abstract}

Key words: UK; Conversation Analysis; troubles-telling; nurse-patient interaction. 


\section{INTRODUCTION}

The preoperative assessment (POA) exists in most healthcare systems and is completed prior to planned surgery to ensure that the patient is fully informed about the upcoming procedure and that potential risks for surgery are properly assessed. The POA is part of a perioperative system of care aimed at monitoring and mitigating the associated health and mortality risks as well as reducing cancellations, shortening 'patient pathways' to treatment and speeding up post-surgery recovery, all of which in turn improve resource efficiencies (Findlay et al, 2011; Malley et al, 2015).

A range of healthcare professionals may carry out the POA, though in the UK, the role is increasingly allocated to specially trained nurses (Abraham, 2013), who are particularly suited to the communicative / therapeutic demands of the role (Bramhall, 2002; Mottram, 2009).

The POA involves a medical examination and assessment of the patient's suitability for surgery approximately three weeks before an operation. It comprises routine procedures such as measuring blood pressure and carrying out ECGs, as well as questions about the history of the patient's health (especially previous surgery/anaesthetics), and about current medication and conditions. Determining fitness for surgery is crucial for patients at risk of adverse outcomes, hence communication is key for the efficacy of POAs (Chan et al, 2011). Poor communication can contribute to, or cause, adverse events in treatment (Lingard et al, 2008) and can exacerbate patient anxiety (Carr et al, 2006; Gilmartin \& Wright, 2008). Good communication can reduce patient anxiety prior to surgery (Mottram, 2009; Chan et al, 2011), help manage patient expectations and identify their needs (Malley et al, 2015). 
The studies above focus on the communicative role of nurse practitioners in POAs, and often identify their success in providing a 'holistic' service of care (Hines et al, 2013: 74), preparing patients psychologically, and identifying potential risks through the gathering of accurate and full data. However, very little existing research on communication in the POA addresses actual interactional data (though see Benwell \& McCreaddie, (2016); also Jones, (e.g. 2007) on similar hospital admissions processes). The current study opens up this interactional 'black box' to closer analytical scrutiny by using conversation analysis to examine exchanges between nurses and patients in the UK health system. Our analysis reveals strategies for efficiently and empathically gathering relevant information from potentially anxious patients. We focus specifically on sequences in which patients give expanded responses to the checklist questions posed by the nurses. Our analysis examines how nurse and patient collaboratively negotiate the relevance of the patient's expanded response to the immediate institutional agenda of assessing fitness for surgery.

\section{Questioning in medical interaction}

Interaction in POAs shares with other medical interactions the property of being a highly question-driven form of interaction (Roter \& Hall, 2006; Stivers \& Majid, 2007). Questions set the agenda for the patient in relation to both the topical domain and the type of action expected in the response (Stivers \& Heritage, 2001). In their design, questions also embody the medical professional's presuppositions vis-à-vis the patient and their epistemic stance towards the information solicited in the question, as well as setting a preference for the polarity of the response (Heritage, 2010). For example, a question about asthma designed as “you don't have asthma do you" (Heritage, 2010: 57) seeks confirmation (through the tag 
question) of a relatively confident assumption about the patient not having asthma (the epistemic stance displayed by the declarative formatting).

These issues of question design are also influenced by the type of medical encounter (e.g. 'well visits' vs 'acute visits') and the stage of the medical encounter (e.g. history taking vs diagnosis). Heritage (2010) explains how they are differently influenced by two key principles: optimisation (Heritage, 2002) and problem attentiveness (Stivers, 2007). Optimisation refers to the observation that unless a physician has reason to believe otherwise, they typically formulate their questions to favour "“no problem" responses' (Boyd \& Heritage, 2006: 162). This is illustrated in the example above, in which the doctor's question is grammatically designed to favour a 'no asthma' response. Boyd \& Heritage (2006) show that this is the default principle of medical questioning, evident during medical history taking and routine information gathering appointments (with the notable exception of lifestyle questions relating to smoking and drinking, which are rarely optimised (Heritage, 2010)). In contrast, in acute visits, patients present with a problem for which diagnosis/treatment is sought. In these contexts, problem attentiveness dictates that questions relating to the patient's primary symptoms are designed to presuppose a problem. In the POA, diagnosis/treatment has already been addressed; the function of the POA is to determine that there are no additional concerns that might prevent surgery taking place. In other words, the patient's current health problem is not the focus of the questioning. Thus, the design of the nurses' questions is not typically problem-attentive but rather is oriented to optimised information gathering.

An additional factor in information gathering/medical history taking is orientation to the routine, 'checklist' nature of the interactional task where the content of the questions is 
governed by a procedure or even an actual form to be filled in. This has consequences for the design of the questions and also for the opening sequence. Specifically, health visitors (Heritage \& Sefi, 1992; Raymond, 2010) and nurses (Jones, 2007) are observed to preface the questioning with reference to the bureaucratic, imposed nature of the task. In addition, successive questions are often linked through and-prefacing (Heritage \& Sorjonen, 1994) or a reduced grammatical form that is anaphorically dependent on the preceding question (Stivers \& Heritage, 2001) and marks the question as one in a 'checklist series' of questions.

In all this, Heritage (2010: 46) observes that 'physicians and patients both cooperate and struggle with one another over "what matters" in a given medical context'. In other words, whilst the health professional ultimately decides what information will be recorded on the form, in designing and responding to the questions, both parties are involved in negotiating the value of the information exchanged in relation to the institutional goals of the medical encounter.

Our analysis shows that POA questioning involves a routinized, checklist style of optimised questioning but with some important departures in the patterns of sequence organisation and action-orientation that bear directly on the 'negotiation of what matters'.

\section{Activities and the institutional agenda}

While questions in medical encounters set the agenda for the ongoing talk, patient responses sometimes extend beyond the restrictions imposed by the professional's optimised first position turn. Stivers \& Heritage (2001) suggest that these extended responses are either 
expanded answers, which are nonetheless aligned to the checklist agenda, or narrative expansions, which fully depart from the checklist agenda and are oriented to the patients' 'lifeworld' (Mishler, 1984) concerns. Expanded answers are oriented to difficulties in responding that prompt additional details but still address the agenda of the question, whereas narrative expansions introduce aspects of the patient's own agenda into the interaction (cf. Nishizaka, 2011; Bonnin, 2014). However, both types of extended response may introduce elements of the patients' lifeworld and both are oriented to as accountable, so the distinction is perhaps one of degree rather than discrete categories of response. Our analysis shows that, in the POA, the alignment or otherwise of a patient's response to the agenda of the nurse's question emerges as a collaborative outcome of the interaction between nurse and patient.

Stivers \& Heritage (2001) suggest that narrative expansion displays a progressive transition from formulaic history-taking into interaction that is more conversational in form. Ten Have (1989) discusses a similar mixing of interactional frameworks during GP consultations. However, rather than a transition from one interactional framework to another, he suggests that doctor-patient interaction systematically involves ongoing convergence (Jefferson \& Lee, 1981) between two distinct activities (consultation and troubles-telling). Both Stivers \& Heritage and ten Have thus demonstrate that participants in medical settings shift between the institutional/medical agenda (history-taking/consultation) and the patient's agenda (narrative/troubles-telling). Our own data shows a similar shifting between the checklist agenda of the pre-operative assessment and the patient's agenda, observable in shifts between the type of checklist oriented Q-A sequences described above and troubles telling, but we argue that the distinction emerges as a product of negotiation rather than an a priori property of any particular turn at talk. 


\section{Troubles-telling in Medical Encounters}

'Troubles-talk' refers to a particular kind of extended sequence involving personal disclosure of difficult, intimate or embarrassing episodes or problems (Jefferson, 2015). Crucially, Jefferson \& Lee (1981) argue that it is not the content of the talk per se that makes it a troubles-telling but the projected trajectory of the talk and the locally invoked categories for the participants (e.g. troubles-recipient). This is particularly relevant to our analysis as we focus on patients' extended responses introducing potential health problems. In other words, the content of these responses 'might be pre-classified as a trouble' (p.403) but its actual status is a matter of interactional negotiation.

In other medical settings, troubles-telling has been examined as a central activity of the problem attentive phase of the encounter, leading to diagnosis/treatment (Ruusuvuori, 2005, 2007; ten Have, 1989). Questioning in the POA, however, is not typically problem attentive, nor is diagnosis/treatment relevant, as the focus is on 'fitness for surgery'. Troubles-oriented talk nonetheless occasionally emerges in the context of patients' expanded responses which potentially challenge their fitness for surgery. In these contexts, the nurses observably orient to the institutional goal of probing for and recording potentially relevant information.

In the analysis that follows we demonstrate how routine preoperative sequences normatively orient to an 'optimised' design involving 'no-problem' or minimally expanded answers to checklist questions, but that where responses are expanded and dispreferred, troublesoriented talk may be deployed as a resource for negotiating 'what matters' to this local agenda in the context of the epistemic and institutional asymmetries of this particular setting. 


\section{DATA AND METHODS}

Data from fifteen POAs with six different nurses were audio-recorded from an NHS hospital in Scotland. Ethical permission to audio-record (but not video-record) and transcribe was obtained from the NHS ethics board and informed consent was secured from all participants in advance (via letter). Anonymity for all participants (including third parties) was assured by the alteration of potentially identifying details. The recording equipment was left with the nurses to record their own sessions and they were responsible for confirming consent with patients before the session commenced.

The data are transcribed and analysed using conversation analysis (CA), an approach which studies the sequential patterning of turns at talk to reveal members' understandings of the interaction (Sidnell \& Stivers, 2013).

\section{DATA ANALYSIS}

In what follows we first demonstrate orientation to optimised checklist questioning before considering examples where patients depart from this normative orientation with dispreferred, expanded responses. We then examine the interactional resources deployed by nurses and patients to negotiate the relevance of these expansions to the medical agenda. 
Robinson (2006) demonstrates how the opening sequences of primary care visits index clinicians' understanding of patients' reasons for the visit. Similarly, in POAs, nurses explicitly frame the interaction by referring to institutional goals of form-filling and information-checking, as in Extract 1 (see also Extract 4, 1.1):

\section{Extract 1}

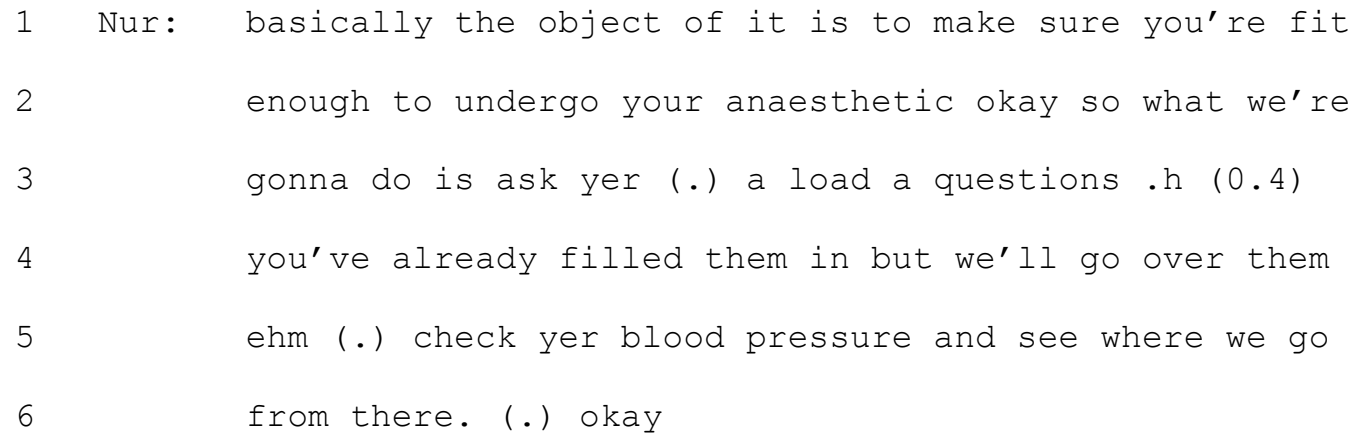

The nurse's orientation to the process as a bureaucratic requirement is displayed through her use of the institutional first person plural subject (Wilson, 1990) and informal, semantically loaded lexical choices ("a load a questions"). Heritage \& Sorjonen (1994) suggest that, rather than undermining patient-centredness, invoking the bureaucratic nature of the task distances it from the nurse and preserves the overarching emphasis on affiliative relationship-building.

The subsequent interaction displays the features of a routine, checklist medical encounter, including minimisation, and-prefacing and optimisation. Extract 2 illustrates minimisation in the design of both the nurse's questions and the patient's response. 


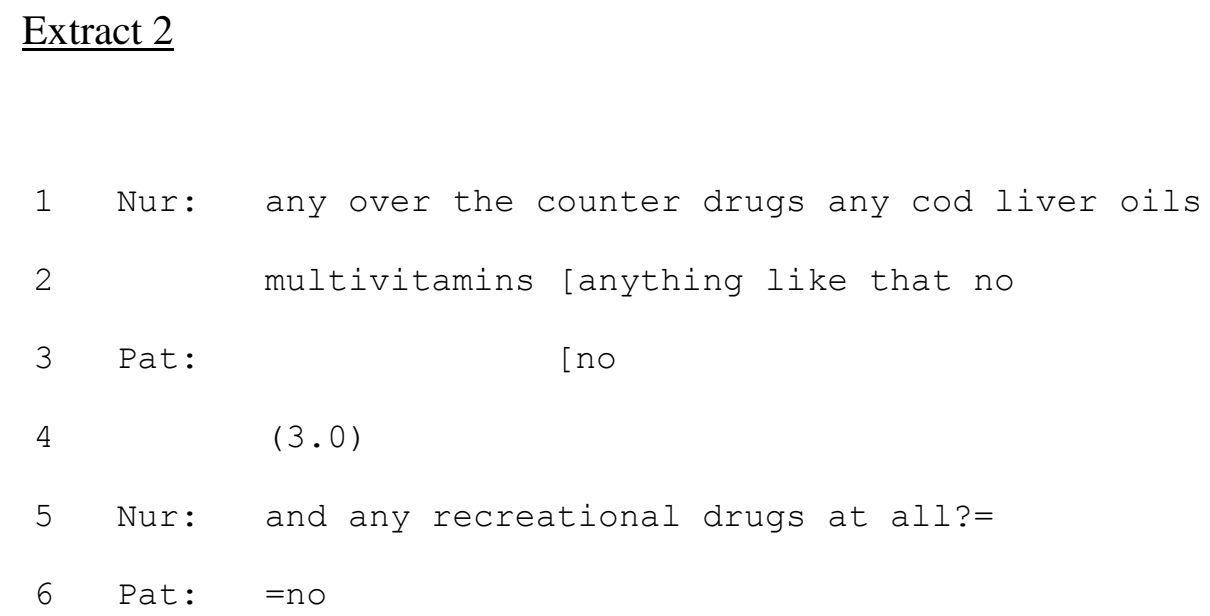

The nurse's questions are grammatically reduced polar interrogatives designed to elicit unelaborated yes/no responses. Line 5 also illustrates and-prefacing, which invokes the agenda-based character of the question and its status as a "routine next" in a series of questions, thereby also treating the preceding response as unproblematic and sufficient (Heritage \& Sorjonen, 1994). In addition, the formulation of the nurse's questions with the indefinite negative polarity item any projects a no response, conforming to the 'no-problem' orientation of the principle of optimisation (Bolinger, 1956; Heritage et al., 2007).

Extract 3 shows the normative force of the principle of optimisation:

\section{$\underline{\text { Extract } 3}$}

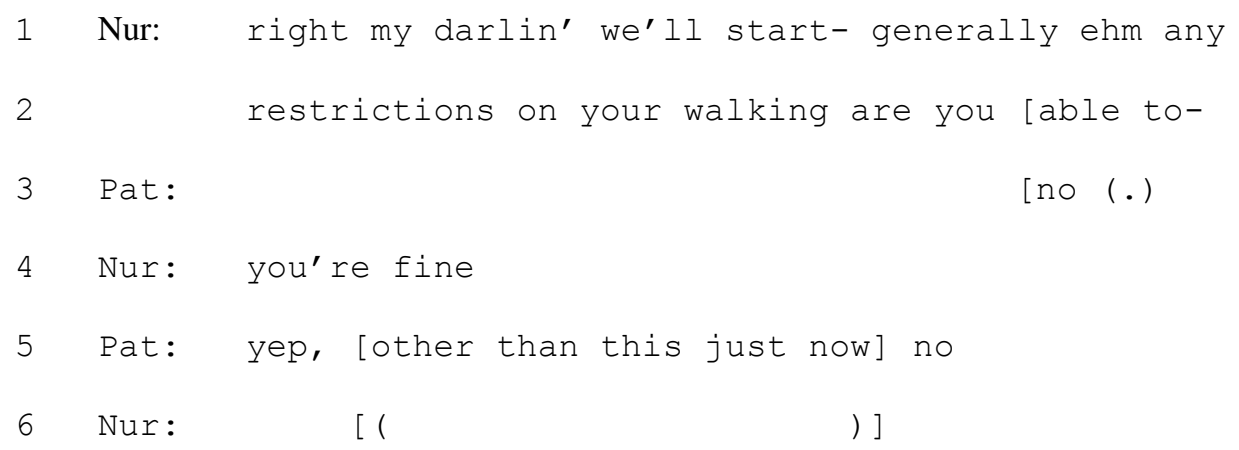


The nurse initially formulates her question with any ("any restrictions") and then moves straight into a reformulation "Are you able to-" in overlap with patient's minimised preferred response "no". The overlapped reformulation is repaired to the declarative question "you're fine" which formulates the upshot of the initial Q-A sequence but switches the polarity of the preferred response. The nurse's incomplete question seems likely to have been aimed at a reformulation providing an optimised alternative question taking into account the patient's presenting problem. The patient expansion may also be oriented to the apparent contradiction between the optimised responses and the reported "this just now" or to the switch in polarity of response occasioned by the nurse's turn design. Crucially, the initial and subsequent formulations are oriented to no-problem outcomes which the patient produces one after the other before qualifying with an expansion (1.5) referring to her current problem with walking. Thus, the patient conforms to the principle of optimisation despite surgery-related problems with walking. In other words, neither participant orients to the POA as problem-attentive.

\section{Departures from 'routine' data gathering}

In the previous examples, the turns of both patients and nurses were oriented to 'routine', minimal, no-problem responses, and the sequence accordingly involved a rapid exchange of turns with little elaboration. Sometimes, however, patients produce dispreferred responses that extend beyond the projected restrictions of the question design. In our data, the nurses' uptake of patients' extended responses shows a mixture of information-oriented or troubles- 
oriented receipts. Information receipts consist of minimal responses (e.g. 'right okay'), repetition and pursuit of expansion through contingent questions (Heritage \& Sorjonen, 1994). Troubles-oriented receipts consist of empathic acknowledgement or assessment of the trouble as trouble (Jefferson, 1984). Our analysis reveals that these different forms of uptake implicitly index the patient's non-minimal response as either an extended answer aligned to the agenda of the question or as a narrative expansion that has moved away from the medical agenda.

\section{Information-oriented uptake}

In the following extract, the patient confirms a slight hearing problem which the nurse follows up with a contingent question about hearing aids (1.5). This contingent question is designed for a yes-no response, but receives a transformative, non-conforming response. Grammatically nonconforming responses index a potential problem with the original question (Raymond, 2003), while transformative answers, resist not just the grammatical design of the question but also the terms or the agenda of the question, and so provide clues to the problems with the direct answer (Stivers \& Hayashi, 2010):

\section{Extract 4}

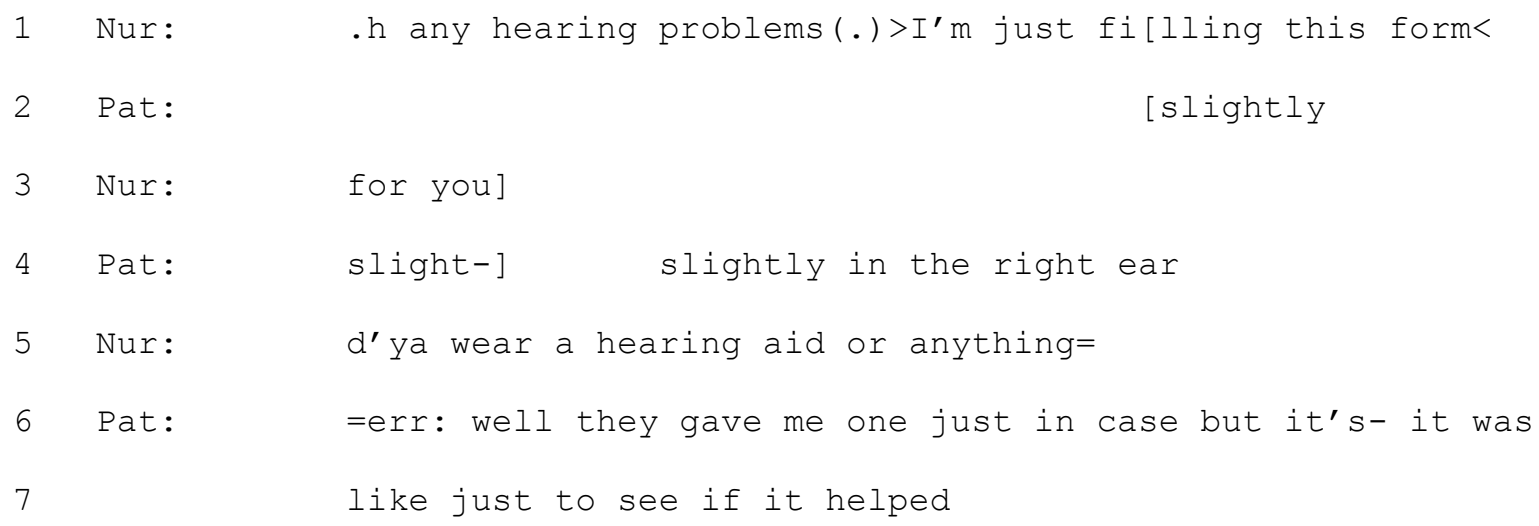




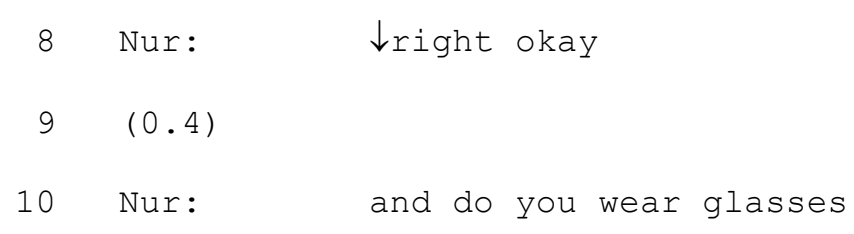

The patient's transformative answer (1.6) is oriented to difficulties with the potential implications of a simple fitted 'no' response. The contingent question is sequentially positioned to be understood as further probing his deafness and its relevance for surgery. Hence a fitted 'yes' or 'no' response would not merely confirm or disconfirm the hearing aid but would be oriented to the agenda of the extended sequence. The transformative response is designed to resist the implications of this agenda.

The important observation for our analysis is that the nurse's uptake (1.8) takes the form of a composite sequence closing third (SCT) (Schegloff, 2007): "right okay". "[R]ight" is a response token that marks epistemic progression and "okay" marks possible closure by claiming acceptance of the preceding second pair part as responsive to the first. In this way, the nurse orients to the information about the hearing aid as having answered the checklist question (presumably having inferred a likely "no" response). On the other hand, the patient's non-conforming response is a dispreferred SPP and these are typically oriented to as expansion relevant. However, through the SCT and the noticeable absence of sequence expansion, the nurse conveys that the requirements of the checklist question have been met and that expansion of the volunteered information is not relevant. In other words, the nurse resolves the patient's struggle with providing a fitted response by marking the sequence as complete; her SCT simultaneously marks receipt of an answer and signals that the additional detail in the patients' response does not 'matter' to the checklist. The patient correspondingly orients to the sequence as closed. In contrast, in the following extract, the nurse's 
information-oriented $3^{\text {rd }}$ position responses are expansion-oriented and elicit further details from the patient.

This extract begins with the nurse's question which has the declarative formatting typical of an optimized question. However, the patient does not respond with the preferred minimal, 'no problem' response for which the question is designed, but offers additional information 'only when I'm running'. This triggers non-minimal post-expansion to elicit further information (a fuller version of this extract is examined in detail later in this paper):

\section{$\underline{\text { Extract } 5}$}

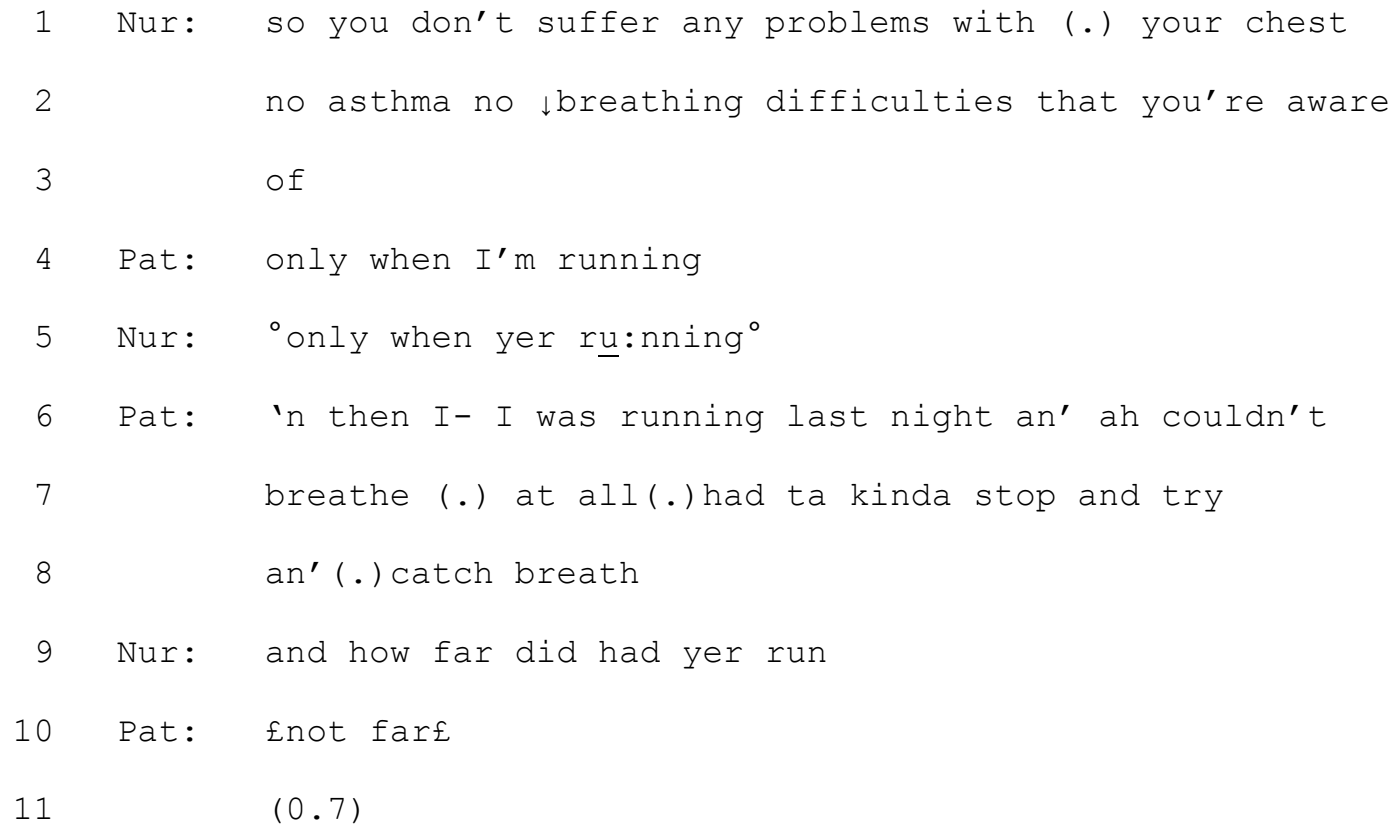

The mixture of preferred and dispreferred features of the patient's response in line 4 point to the patient's struggle to fit her response to both the immediate sequential context and the overarching institutional agenda. Firstly, it is a disaligned response that reports on breathing difficulties so disagrees with the optimized assumption of the nurse's question. In addition, 
similar to extract 4 , it is a transformative, non-conforming response to a yes-no question, so indexes a problem with the question. On the other hand, the response remains clearly within the agenda of the question, suggesting that the problem is with the terms of the question. Moreover, although it is a dispreferred, disaligned response, it is produced in a preferred format and is prefaced with "only" which minimizes the consequences of the disagreement. This suggests that the patient is implying that the breathlessness is not relevant to her operative safety and hence is still oriented to the principle of optimization at the level of the institutional medical agenda (cf. Lee (2011) on transformative answers and orientation to higher level institutional goals).

The nurse's quiet third position repetition (1.5) displays the recordable relevance of the information for the checklist but does not implicate sequence closure and elicits further information from the patient (perhaps oriented to the accountability of the preceding dispreferred second). This begins as an and-prefaced continuation of the generalized account of the patient's breathlessness when running, but then the patient self-repairs and initiates a narrative description of a single incident. The patient's response here is no longer oriented to optimization. Indeed, the narrative potentially constitutes a move away from the agenda of the question. However, it is still topically relevant and the nurse indexes topical coherence by the and-prefaced question in line 9 that ties the implications of the narrative back into the checklist activity and receives a more checklist-conforming unelaborated response from the patient. In this way, the relevance of the patient's responses to the checklist emerges as a negotiated outcome of the patient's talk and the nurse's uptake.

\section{$\underline{\text { Troubles-oriented uptake }}$}


The next extract provides a clear contrast with the information-oriented stance of the nurse in

\section{Extracts 4 and 5:}

\section{$\underline{\text { Extract } 6}$}

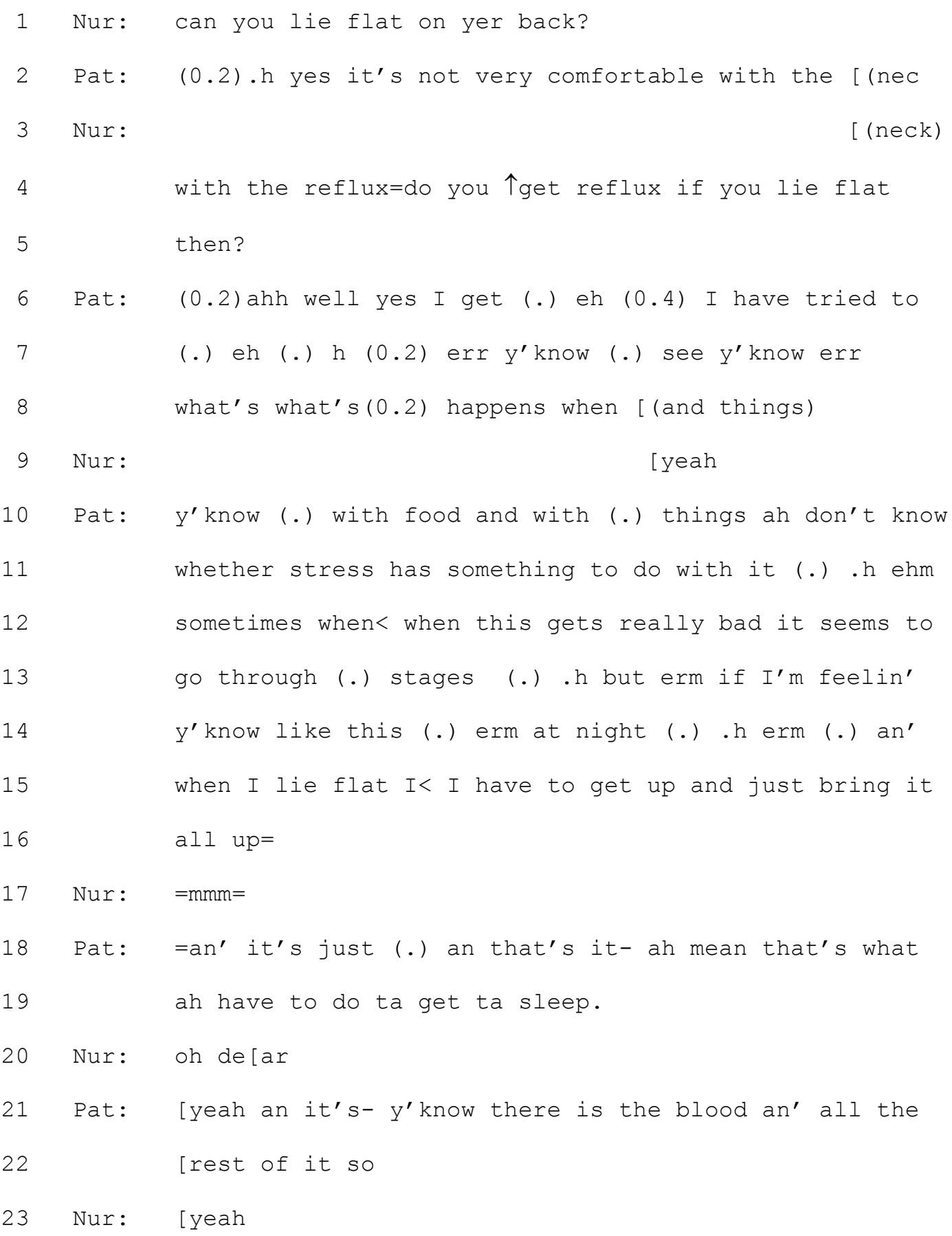




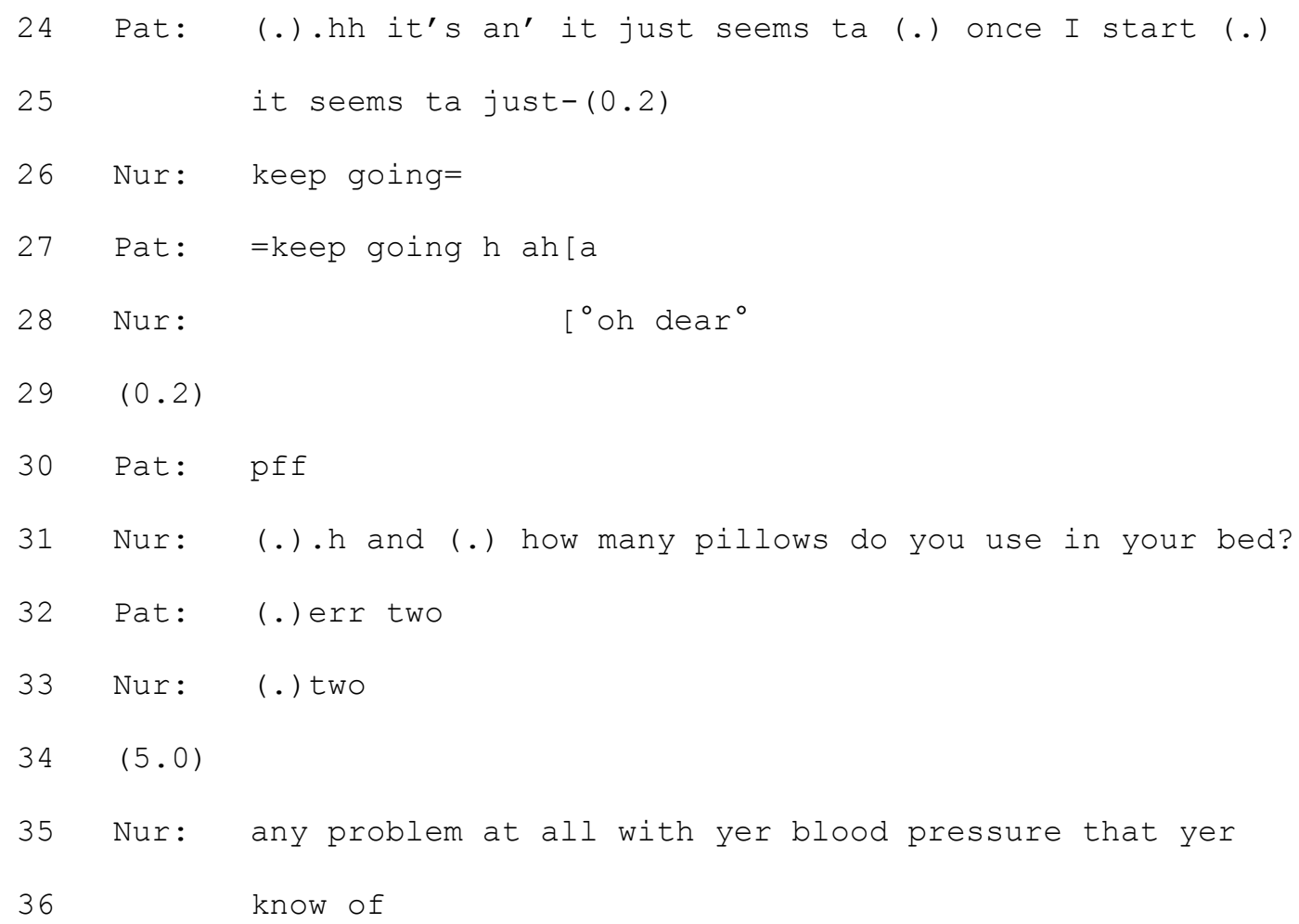

This extract begins with a polar interrogative designed for an optimised yes response. The patient produces the preferred "yes" but prefaced with a short delay that anticipates the less optimal expansion, "it's not very comfortable with the (neck)". This appears to be a reference to the patient's condition as the nurse produces an overlapping reference to the patient's problem with reflux and immediately reformulates her question as an upshot of the patient's ambivalent response. This reformulation (11.4-5) is problem attentive; it does not presuppose a 'no problem' response, and the patient begins an expanded response that is hearably populated with numerous hesitations, restarts and vague formulations, though still oriented to the agenda of the question. On line 13 , the patient starts to move to a more experienceoriented narrative, prefaced with sometimes, but the narrative is still designed to display orientation to the agenda of the question through overt reference to its original wording "when I lie flat" (1.15). At the conclusion of the patient's narrative, the nurse offers an affiliative and sympathetic acknowledgement of the patient's talk as troubles-talk, "oh dear" 
(1.20), invoking their own status as a troubles-recipient. In this way, the nurse orients to the narrative as a troubles-telling rather than as informative for the POA. The patient follows this first 'oh dear', with a responsive 'yeah' that responds to and overlaps with the nurse's "oh dear" and then a continuation which offers more 'doctorable' features of the condition (1.21: “blood an' all”) (Heritage and Robinson, 2006: 57). The nurse however responds with a collaborative completion of the patient's turn "keep going" (1.27) and a second "oh dear", thus still orienting to the patient's description as a troubles-telling. The troubles-oriented sequence is then concluded as the nurse returns to the medical agenda with a related but new 'and-prefaced' question about the number of pillows used by the patient. The nurse's minimal troubles-oriented responses thus convey that the details offered by the patient are not relevant to the immediate medical agenda and so provide a resource for negotiating relevance whilst crucially maintaining empathy.

This analysis shows that the 'business at hand' involves information that is sometimes troubles-oriented but is not, in the first instance at least, sequentially produced as a troublestelling. This is particularly relevant in problem attentive medical questioning such as is seen in lines 4-5. The nurse's question about reflux elicits troubles implicative information but as argued by Jefferson and discussed above, it is not the content but the sequential organisation and forms of uptake that mark talk as a troubles-telling. Troubles-telling as an activity is thus invoked by the participants at certain points in the interaction. At these points, participants observably negotiate the institutional/social relevance of the troubles-related talk and the categorial roles and identities implicated therein. In particular, the recognisability of the elements of a troubles-telling sequence appears to provide the participants with a strongly affiliative resource for disengaging from the institutional task of information-gathering. 
Jefferson (1988) describes the trajectory of troubles-telling in three stages: announcement; exposition; affiliation response. Each stage involves a stepping up of 'interactional intimacy' collaboratively negotiated by troubles-teller and troubles-recipient. An initial troublesoriented uptake of an announcement commits the recipient to the locally accomplished status of troubles-recipient and elicits exposition of the trouble. This in turn receives heightened affiliation by the recipient that elicits further expansion of the troubles-report. It is this further expansion, the affiliation response, that is the 'topical and relational heart of troubles-telling' (p. 43) and it emerges as a response to the increased level of empathy/affiliation in the uptake of the exposition relative to the uptake of the initial announcement.

In our data, troubles-telling is invoked when the nurse orients to a patient response with a display of troubles-recipiency. Thus, in extract 6 , as the patient moves away from the medical agenda, the nurses' responses overtly orient to the patients' talk as a troubles-telling through a display of empathic acknowledgement ("oh dear"). In this way, the nurse orients to the patient's talk as a troubles-announcement and elicits exposition of the trouble (1.21). In other words, the initial troubles-oriented uptake by the nurse (line 20) provides the patient with the 'go-ahead' to expand their response while also marking it as moving away from the medical agenda.

In so doing, the nurse invokes a shift from her institutional role as nurse to a locally accomplished identity as troubles-recipient. Crucially, the nurse's troubles-oriented uptake addresses that part of the patient's response which is affect-oriented rather than receipting the response as information relevant to the history taking. Interestingly, following the nurse's 
initial move to troubles-recipiency, the patient appears to attempt to realign their talk with the information-oriented medical agenda through the repair in line 21 that shifts focus from the experiential to the physical/doctorable ("blood an' all that"). However, the nurse does not correspondingly revert to information-oriented uptake but responds to the patient's on-going narrative with a continuer (1.23), an affiliative co-completion (1.26) and finally a second "oh dear" (1.28) which receipts the narrative as a troubles-exposition. In this way, the nurse and patient tease apart information and affect and collaboratively negotiate that the move to troubles-recipiency marks official absence of uptake of the medical/‘doctorable’ information.

However, invoking troubles-recipiency also brings a new and equally delicate task of exiting from the troubles-talk to return to the checklist without appearing to disregard the patient's concerns. Exiting from troubles talk in other medical settings, e.g. primary care, may be accomplished via institutionally mandated activities such as advice giving or diagnosis and remedy (Ruusuvuori, 2005, 2007). However, such activities are not relevant in the POA which is solely oriented to information gathering. In contrast to the ideal schema that Jefferson describes, the nurses in our data use the same response form for the uptake of both announcement and exposition. In other words, the increase in empathy that Jefferson observed to mark the shift from troubles-recipiency to affiliation is noticeably absent in the nurse's responses. Moreover, the patients orient to this noticeable absence of heightened affiliation as closure implicative. In other words, while the first troubles-receipt invites elaboration of the trouble, the repeated receipt format appears to block the move to 'affiliation response'. Instead the patient (1.30) produces just the very minimal “pff” leaving the nurse free to move the "relevant next" in the medical questioning, a question about pillows. 
Whilst the noticeable absence of increased affiliation in the uptake of the exposition of a troubles-telling risks being interpreted as a lack of empathy, or as a 'synthetic', professionally mandated empathy, the nurse combines the repetition with a highly local, recipient-designed display of empathy/ intersubjective understanding: the collaborative completion, "keep going” (1.27). In this way, the nurse sensitively accomplishes what might otherwise be seen as a premature exiting from the troubles-telling sequence.

It is striking to note that it is not merely the practice of responding with a troubles-oriented uptake that recurs here and elsewhere in our data but rather the full sequential trajectory:
A. Pat: extended response
B. Nur: troubles-oriented uptake
C. Pat: troubles exposition (with reference to doctorability)
D. Nur: repeated troubles-oriented uptake (combined with local, recipient- designed display of shared understanding)

For example, in the following extract (analysed in Benwell \& McCreaddie, 2016), the nurse repeats the troubles-oriented response "what a shame" (1.7 \& 1.10) but also displays shared understanding of the patient's central concern through repetition of "young", while the patient following the initial troubles-oriented uptake focuses on the doctorable "strokes" and seizures" in the troubles exposition:

\section{Extract 7}

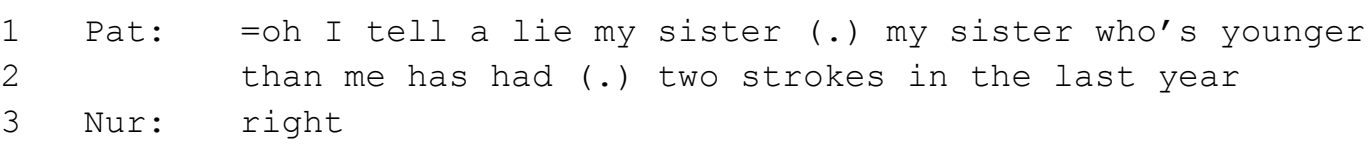




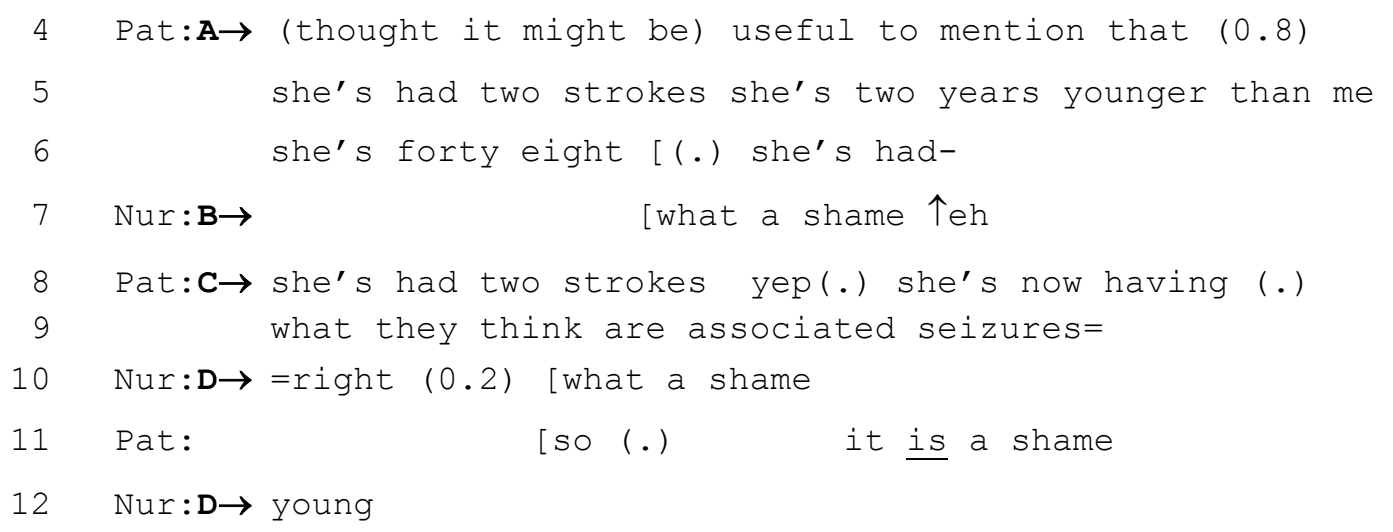

Examining our data in light of the detailed stages of Jefferson's candidate troubles-telling sequence thus shows how invoking troubles-telling (B) provides both interactional space for the patient to articulate their concerns $(\mathrm{C})$ but also the resources to exit from the troublesoriented talk without moving into a full-blown troubles-telling sequence (D). Note that the observation that patients sometimes resist the troubles-telling frame by including overt reference to "doctorable" aspects of their complaint (e.g. Ex.6, 1.21) provides participant orientation evidence of the shared understanding of the implications of invoking troublestelling in these contexts.

On the other hand, closer examination of an expanded version of Extract 5, (given here as Extract 8), suggests that troubles-talk also provides the patient with interactional resources to resist the checklist agenda (cf. Pilnick and Coleman, 2006). As noted above, this sequence begins with a transformative, non-optimal response to the nurse's question about breathing difficulties. This triggers an extended series of information-oriented, contingent questions by the nurse $(11.9,13,26)$ before arriving at the nurse's no-problem summary (11.34-36):

\section{$\underline{\text { Extract } 8}$}




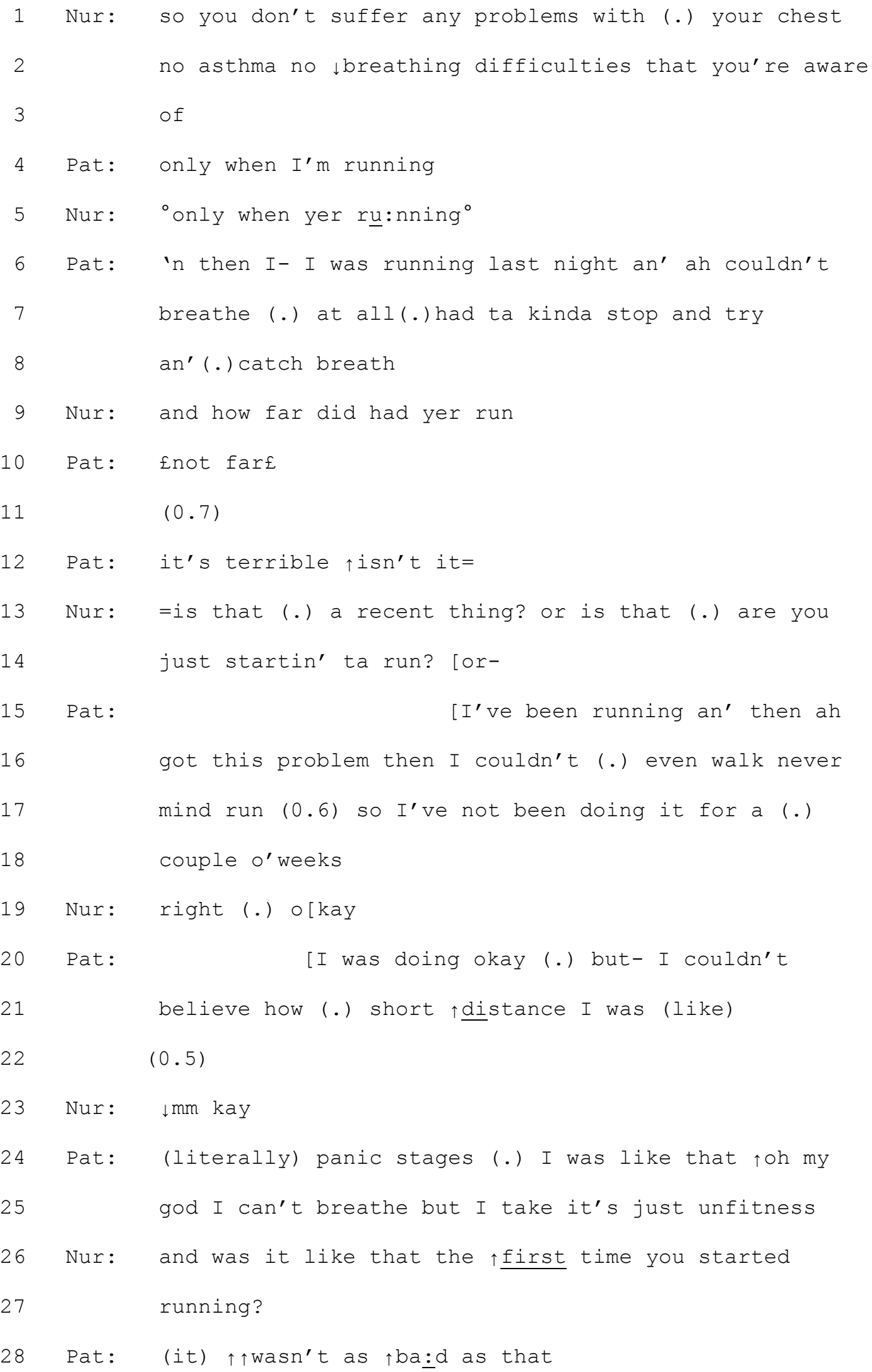




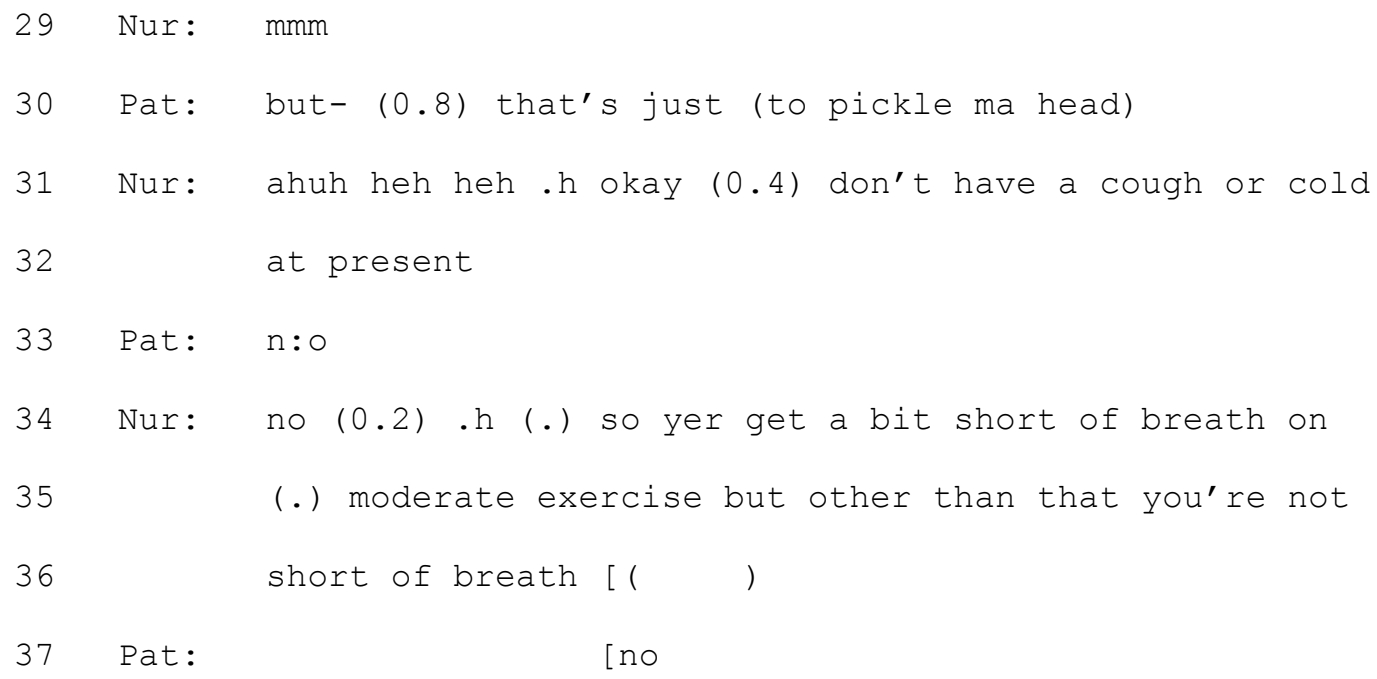

The overall trajectory of the sequence is thus oriented to information gathering and the nurse consistently remains within the interactional framework of the checklist agenda, producing either information receipts or contingent questions. However, the patient's expanded responses move between information-oriented reporting and troubles-oriented narrative. Ten Have (1989) suggests that troubles-telling 'dramatizes the suffering and emotionally involves the teller'. Here, the patient's responses repeatedly display a shift away from the generic temporal reference and information checking of the questions and into more conversational formats involving dramatic combinations of reported thought and extreme case formulations focused on the subjective, situated experience of the patient.

In lines 6-8, the patient begins with an and-prefaced continuation of the generalized account of her breathlessness, but then self-repairs and initiates a troubles-oriented narrative description of a single incident in which the problems of breathlessness are produced with an Extreme Case Formulation (ECF) (Pomerantz, 1986) (1.6-7: “couldn't breathe at all”). The nurse responds with an information-oriented contingent question which receives a minimal information-oriented response by the patient who then moves away again from the checklist 
agenda, producing a negatively dramatizing assessment (1.12). This realigns the patient's talk with the troubles-talk in lines 6-8 but might also be interpreted as closure implicative, i.e. as an attempt by the patient to close down further probing of her breathlessness as relevant to the POA. (Note, our analysis is hampered here by the lack of video as it is not clear whether the nurse is writing on the form at this point. Ten Have (1989) suggests that troubles-talk occurs in gaps in medical talk where the professional is occupied with other tasks.) The nurse, however, does not respond to the assessment in line 12 and proceeds with informationoriented questioning about the patient's running. The patient complies, providing further information $(1.15$ - 18) before moving again into narrative expansion with descriptions of reported thought ("I couldn't believe how short distance", "I was like that oh my god I can't breathe") and ECFs ("literally panic stations" "can't breathe").

The suggestion that these troubles-oriented narratives about a specific running experience work up a display of potential non-relevance by the patient is further foregrounded by the patient's assessment, "but I take it's just unfitness" (1.25), which invokes a contrast between fitness issues and medically relevant issues. The minimiser adverb "just" indicates that there is nothing more to say, so is also hearable as closure-implicative (Drew, 1992; Lee \& Sheon, 2008). The nurse again does not respond to the assessment but produces a further checklistoriented, and-prefaced question which again receives an informative response (1.28) and another hearably closure-implicative assessment with "just", to which the nurse responds with laughter and an aligned move to close both the topic of running (1.31) and the checklist item about breathlessness (11.34-36). 
There are several interesting recurring features in this sequence. Firstly, the sequence cycles through a recurring pattern in which the patient moves from a report of a potential trouble that is fitted to the checklist agenda to a more conversational narrative that orients to the trouble as relevant to the patient's 'lifeworld' concerns with fitness (Mishler, 1984) before producing a bid for closure. In other words, the patient appears to bring into focus their lifeworld concerns with the impact of their health problem on their fitness and simultaneously display resistance to the immediate medical relevance of those concerns for the POA (cf. Denvir (2012) on the normal/healthy stance enacted by patients in response to substance use history taking). The nurse's uptake on the other hand consistently orients to the informational relevance of the patient's responses for the checklist. This elicits further talk from the patient showing that the nurse's information-oriented uptake is treated by the patient as expansionrelevant. Thus the negotiation of relevance emerges as a collaborative outcome of the patient's troubles-related talk and the nurse's uptake. Moreover the sequential working out of the tension between information-orientation and troubles-orientation evident in this extract indexes the complex layers of epistemic and institutional asymmetry tied to this institutional setting (Sidnell, 2012).

\section{Invoking troubles-telling in patient responses}

While the distinction between information-orientation and troubles-orientation is unambiguous in nurses' uptake of patients' responses, the distinction between reporting on potential problems (in line with the checklist) and invoking troubles-telling (moving away from the checklist) in patients' talk is less straightforward. A dispreferred SPP to a checklist question inherently introduces what ten Have (1989) calls a 'report about a self-experienced trouble' but such reports can be, and are, produced without invoking troubles-telling. For 
example, the initial report of breathlessness in Extract 8 does not invoke troubles-telling. A report about a potential trouble is argued to become recognisably a troubles-telling when it involves a shift in focus from the trouble to the person (Jefferson, 1980). However, the boundary between focus on the trouble and focus on the person is not always clear. Ten Have (1989) also suggests that troubles-telling is invoked when patients provide more information than is strictly necessary for the medical encounter. Our contention, however, is that ten Have's assessment, 'more information than strictly necessary', is not made from the patient's perspective. Our analysis indicates that patients are typically oriented to providing a response within the agenda of the question (e.g. Ex6, 1.15) but that non-minimal responses and SPP increments index difficulty with providing a fitted response. The data also showed that potentially troubles-oriented responses do not inherently invoke a shift to the activity of troubles-telling.

By contrast, in Extract 8, the patient's SPP increments deploy a range of marked features such as narrative formatting, ECFs and reported thought which offer 'exceptional affordances for empathic alignment' (Heritage, 2011 p. 177) and clearly shift the focus from the trouble to the patient as experiencer of the trouble, invoking a local identity of troubles-teller. Our analysis shows that these overtly troubles-telling elements provide the patient with resources to resist the medical relevance of her concerns. In other words, as with the nurses' troublesoriented uptake, the patients' more overt shift to troubles-telling marks a shift away from the checklist agenda, as evidenced by the patient's invoked contrast between medical relevance and "just unfitness" (1.25).

\section{CONCLUSION}


The POA is a crucial stage of the perioperative process designed to reassure patients and identify potential areas of risk. Putting the patient at ease and providing interactional space for patients to raise health concerns is vital. Our data provided significant evidence that patients sometimes present health information in dispreferred expanded responses whose relevance to the checklist must be collaboratively negotiated.

Nurses orient to these potential reports of trouble either as information pertaining to the checklist, or as a troubles-telling for which an expression of sympathy is relevant. The locally achieved contrast between these two types of response, however, is about medical relevance rather than the choice between information-recording versus empathy. Both types of response provide patient-centred resources for curtailing elaboration of unnecessary detail. In extract 4, the nurse's SCT acknowledges the patient's response as relevant and sufficient despite unresolved details in the patient's turn. In extract 6, troubles-oriented uptake of the patient's talk ("oh dear") provides the interactional space for the patient to express their concerns whilst also signalling that the concerns are not surgically relevant. Moreover, the absence of the 'heightened' affiliation that might prompt further disclosure suggests that the nurses are resisting the escalation of such sequences, and reorienting the interaction back to the medical agenda in a way that is nonetheless sensitive and preserves the patients' sense that their concerns are being accommodated.

In extract 8 (also 5), the patient's introduction of troubles-relevant information about her health and lifestyle are notably oriented to by the nurse as potentially medically relevant, but this trajectory is resisted by the patient who develops it as a distinctly troubles-telling 
sequence, partially, we argue, to resist the checklist agenda itself. The tension that arises between two agendas here is particularly fascinating. On the one hand, the patient deploys troubles-telling as a resource to downplay the medical relevance of her breathlessness, whilst simultaneously prioritising her concern with the lifeworld consequences of her presenting problem. On the other hand, the nurse consistently pursues the potential medical relevance of the breathlessness, presumably due to its possible implication for risk associated with surgery.

Troubles-relevant talk by patients has been observed in other studies of healthcare interaction (ten Have, 1989; Stivers and Heritage, 2001; Ruusuvuori, 2005) and the positive benefits accrued when patients' lifeworld concerns bleed into their medical encounters have been noted (Stivers and Heritage, 2001:158; Robinson and Heritage, 2005: 279; Robinson et al, 2015: 719). By providing troubles-oriented responses to patient disclosures, the nurses in our study conform to this patient-centred ethic and create an affiliative interactional space for patients to express their concerns. However, the evidence from our own data also suggests that troubles-talk is largely prompted where patients struggle to provide a fitted response to information-seeking questions. Nurses engaged in POA information gathering have a potentially tricky path to steer between adhering to the checklist in a time-efficient way, and listening to potential concerns open-mindedly and with empathy. The pursuit of the patient's expanded responses in extract 8 shows that at times nurses depart from an orientation to optimised responses where they feel that such information may reveal clues to medicallyrelevant concerns. The deployment of troubles-oriented sympathy tokens, on the other hand, are a sensitive and empathic means of signalling digression from the checklist agenda and reorienting the talk accordingly. 
Our study provides insight into areas worth highlighting for practitioners engaged in preoperative assessments. A patient-centred approach should allow space for patients to reveal potentially relevant health information, which arguably the optimised design of checklist questions may militate against. The analysis shows how patients sometimes struggle to respond within the constraints imposed by checklist questions and highlights the sensitive means by which patients are afforded space to articulate their concerns whilst non-relevant concerns are curtailed and reoriented. The evidence from the interactions analysed here shows that nurses, in our study at least, are already adept and well-practised in these strategies, and that insights from their talk could inform best practice elsewhere.

\section{References}

Abraham, J. (2013) 'Literature review critically exploring and evaluating advanced perioperative roles in United Kingdom (UK)' Journal of Health and Social Care Improvement. 1:1-11.

Benwell, B. \& McCreaddie, M. (2016) Keeping "Small Talk" Small in Health-Care Encounters: Negotiating the Boundaries Between On- and Off-Task Talk. Research on Language and Social Interaction 49(3): 258-271

Bonnin, Juan Eduardo. (2014) Expanded answers to bureaucratic questions: Negotiating access to public healthcare. Journal of Sociolinguistics 18(5): 685-707 
Bolinger, Dwight (1957) Interrogative Structures of American English. Alabama: University of Alabama Press.

Boyd, E. \& Heritage, J. (2006) Taking the history: questioning during comprehensive history-taking. In J. Heritage \& D. Maynard (eds.) Communication in medical care: Interactions between primary care physicians and patients. Cambridge: Cambridge University Press, pp. 151-184.

Bramhall, J (2002) The role of nurses in preoperative assessment. Nursing Times 98(40): 34

Carr, E., Brockbank, K., Allen, S. \& Strike, P. (2006) Patterns and frequency of anxiety in women undergoing gynaecological surgery. Journal of Clinical Nursing 15: 341352.

Chan, Zenobia, Kan, Carmen, Lee, Patrick, Chan, Isabel and Lam, Joyce (2011) A systematic review of qualitative studies: patients' experiences of preoperative communication. Journal of Clinical Nursing 21: 812-824.

Denvir, Paul M. (2012) When patients portray their conduct as normal and healthy: An interactional challenge for thorough substance use history taking. Social Science \& Medicine 75(9): 1650-1659 
Drew, Paul (1992) Contested evidence in courtroom cross-examination: The case of a trial for rape. In Paul Drew, \& John Heritage (Eds.) Talk at work: interaction in institutional settings, Cambridge, Cambridge University Press, pp. 470-520.

Findlay, G.P., Goodwin, A.P.L., Protopapa, K., Smith, N.C.E. \& Mason, M. (2011) Knowing the risk: A review of the perioperative care of surgical patients. A report by the National Confidential Enquiry into Patient Outcome and Death.

Gardner, Rod (2007) The right connections: Acknowledging epistemic progression in talk. Language in Society, 36(3): 319-341.

Gilmartin, J. \& Wright, K. (2008) Day surgery: patients felt abandoned during the preoperative wait. Journal of Clinical Nursing 17: 2418-2425.

Have, P. ten (1989) The consultation as a genre, in: B. Torode (Ed.), Text and Talk as Social Practice: $115-35$, Dordrecht, Foris Publications

Hepburn, A. (2004) Crying: Notes on description, transcription and interaction. Research on Language and Social Interaction, 37, 251-290.

Heritage, J. (2002) Ad hoc inquiries: Two preferences in the design of 'routine' questions in an open context. In Douglas Maynard, Hanneka Houtkoup-Steenstra, Nora K. Schaeffer, \& Hans van der Zouwen. (Eds) Standardisation and Tacit Knowledge: 
Interaction and Practice in the Survey Interview. New York, Wiley Interscience, 31333.

Heritage, J. (2010) Questioning in medicine. In Freed, A. F. \& Ehrlich, S. (eds), Why do you ask?: The function of questions in institutional discourse. Oxford, Oxford University Press, $42-68$.

Heritage, J. (2011) Territories of knowledge, territories of experience: empathic moments in interaction. In Tanya Stivers, Lorenza Mondada and Jakob Steensig (Eds.) 2011. The Morality of Knowledge in Conversation. Cambridge: Cambridge University Press, 159-183.

Heritage, J. and Robinson, J. (2006) 'Accounting for the visit: giving reasons for seeking medical care', in J.Heritage and D.Maynard (eds), Communication in Medical Care: Interactions between Primary Care Physicians and Patients. Cambridge: Cambridge University Press: 48-85.

Heritage, John, Robinson, Jeffrey, Elliott, Marc, Beckett, Megan and Michael Wilkes (2007) Reducing patients' unmet concerns in primary care: the difference one word can make.' Journal of General Internal Medicine 22(10): 1429-1433.

Heritage, J. \& Sorjonen, M. (1994) Constituting and maintaining activities across sequences: and-prefacing as a feature of question design. Language in Society, 23,1-29. 
Heritage, John, \& Sefi, Sue (1992). Dilemmas of advice: Aspects of the delivery and reception of advice in interactions between health visitors and first time mothers. In Paul Drew \& John Heritage (Eds.) Talk at work: interaction in institutional settings. Cambridge: Cambridge University Press, 358-417.

Hines, Sonia, Munday, Judy \& Kynoch, Kate (2013) JBI Database of Systematic Reviews and Implementation Reports 11(9) 73-83.

Jefferson, G. (2015) Talking about Troubles in Conversation. Edited by P. Drew, J. Heritage, G. Lerner and A. Pomerantz. Oxford: Oxford University Press.

Jefferson, G. (1988) On the sequential organization of troubles talk in ordinary conversation. Social Problems, 35(4), 418-442.

Jefferson, G. (1984) 'On the organization of laughter in talk about troubles'. In J.M.Atkinson, and J. Heritage (eds) Structures of Social Action. Cambridge: Cambridge University Press, pp. 346-369.

Jefferson, G. \& Lee, J.R.E. (1981) The rejection of advice: Managing the problematic convergence of a 'troubles-telling' and a 'service encounter'. Journal of Pragmatics $5,399-422$.

Jefferson, Gail (1980) On 'trouble-premonitory' response to inquiry. Sociological Inquiry, $50(3 / 4), 153-185$. 
Jones, A. (2007) Admitting hospital patients: A qualitative study of an everyday nursing task. Nursing Inquiry 14(3):212-23.

Lee, S.-H. (2011). Responding at a higher level: Activity progressivity in calls for service. Journal of Pragmatics, 43, 904-917

Lee, S.H. \& Sheon, N. (2008) Responsibility and risk: accounts of reasons for seeking an HIV test. Sociology of Health and Illness 30(2): 167-81

Lingard, Lorelei, Regehr, Glenn, Orser, Beverley, Reznick, Richard, Baker, Ross, Doran, Diane, Espin, Sherry, Bohnen, John \& Whyte, Sarah (2008) Evaluation of a preoperative checklist and team briefing among surgeons, nurses and anaesthesiologists to reduce failures in communication Arch Surg. 143(1): 12-17.

Malley, Ann, Kenner, Carole, Kim, Tiffany, Blakeney, Barbara (2015) The Role of the Nurse and the Preoperative Assessment in Patient Transitions AORN Journal 102(2) 181 e.1-9.

Mishler, E. (1984) The Discourse of Medicine: Dialectics of Medical Interviews. Norwood, NJ: Ablex.

Mottram, A (2009) Therapeutic relationships in day surgery: a grounded theory study. Journal of Clinical Nursing 18: 2830-2837. 
Nishizaka, Aug. (2011) Response expansion as a practice for raising a concern during regular prenatal checkups. Communication \& Medicine 8: 247-259

Pilnick, Alison and Coleman, Tim (2006) Death, depression and 'defensive expansion': Closing down smoking as an issue for discussion in GP consultations Social Science \& Medicine, 62(10):2500-2512

Pomerantz, A. (1986) Extreme Case Formulations: A way of legitimizing claims'. Human Studies 9(2/3): 219-229.

Raymond, Geoffrey (2003) Grammar and social organisation: yes/no interrogatives and the structure of responding. American Sociological Review 68:939-67.

Raymond, Geoffrey (2010) Grammar and social relations: Alternative forms of yes/no initiating actions in health visitor interactions. In Alice, F. Freed \& Susan Ehrlich (eds), "Why do you ask?”: The function of questions in institutional discourse. Oxford, Oxford University Press, 87-107.

Robinson, Jeffrey (2006) Soliciting patients' presenting concerns. In John Heritage \& Douglas Maynard (eds), Communication in Medical Care: Interactions between Primary Care Physicians and Patients, New York, Cambridge University Press, 2247. 
Robinson, Jeffrey and Heritage, John (2005) The structure of patients' presenting concerns: the completion relevance of current symptoms. Social Science and Medicine 61(2): 481-93.

Robinson, Jeffrey D., Tate, Alexandra and Heritage, John (2016) Agenda setting revisited: When and how do primary care physicians solicit patients' additional concerns? Patient Education and Counselling 99(5) 718-723.

Roter, Debra \& Hall, Judith (2006) Doctors Talking with Patients/Patients Talking with Doctor: Improving Communication in Medical Visits, Westport, Conn.: Praeger.

Ruusuvuori, J. (2005) Empathy and sympathy in action: Attending to patients' troubles in Finnish homeopathic and GP consultations. Social Psychology Quarterly, 68, 204 222.

Ruusuvuori, J. (2007) Managing affect: integration of empathy and problem-solving in health encounters. Discourse Studies, 9 (5), 597-622.

Schegloff, E. A. (2007) Sequence organization in Interaction: A Primer in Conversation Analysis (Vol. 1). Cambridge, England: Cambridge University Press.

Sidnell, J. (2012) Declaratives, questioning, defeasibility. Research on Language and Social Interaction 45(1), 53-60. 
Sidnell, J. \& Stivers, T. (2013) The Handbook of Conversation Analysis Oxford, Wiley Blackwell

Stivers, T. (2007) Prescribing under Pressure: Parent-physician Conversations and Antibiotics. New York, Oxford University Press.

Stivers, Tanya and Makoto Hayashi. 2010. Transformative answers: One way to resist a question's constraints. Language in Society 39: 1-25.

Stivers, T. \& Heritage, J. (2001) Breaking the sequential mold: answering 'more than the question' during comprehensive history taking. Text 2001, 21: 151-185.

Stivers, T. \& Majid, A. (2007) Questioning children. Interactional Evidence of Implicit Bias in Medical Interviews. Social Psychology Quarterly 70, 424-41.

Wilson, J. (1990) Politically Speaking Oxford, Blackwell 


\section{Negotiating relevance in pre-operative assessments}

Bethan Benwell (University of Stirling)

Catrin S. Rhys (Ulster University)

Ethical approval was granted by the East of Scotland NHS Research Ethics Service. 
Data Statement
Click here to don

Data Statement
Click here to download Data Statement: dataprofile.xml

Click here to download Data Statement: dataprofilexml

nload Data Statement: dataprofile.xml

(n)

-

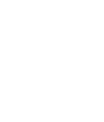

(n)

(1)

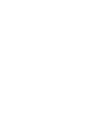

(1)

(1)

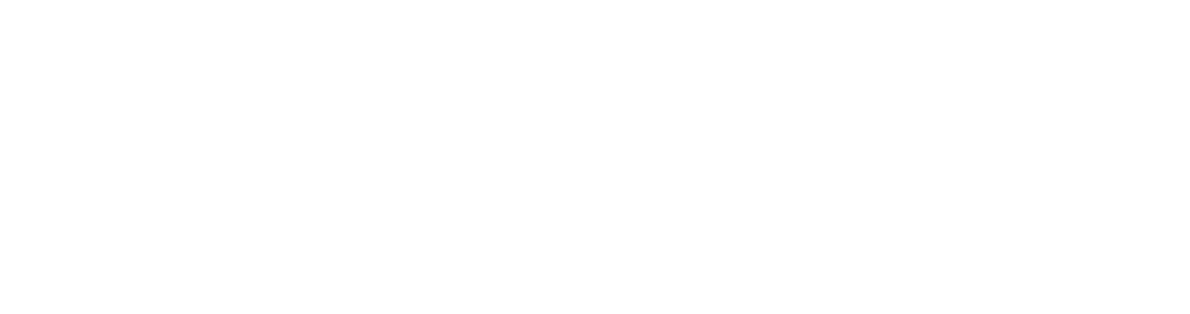

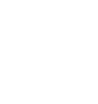

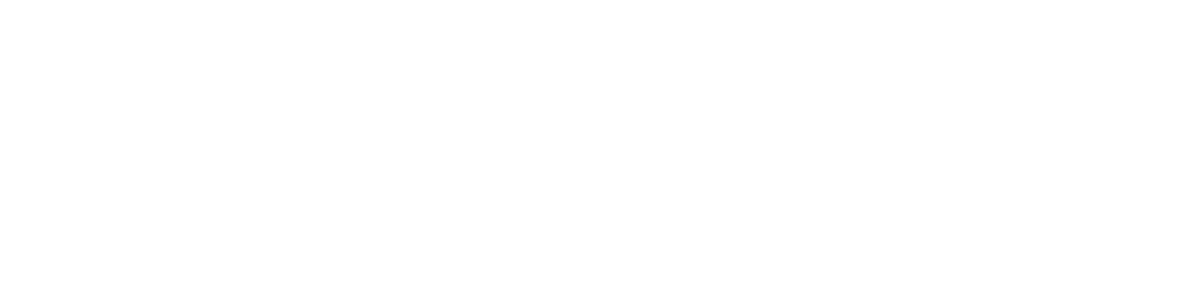

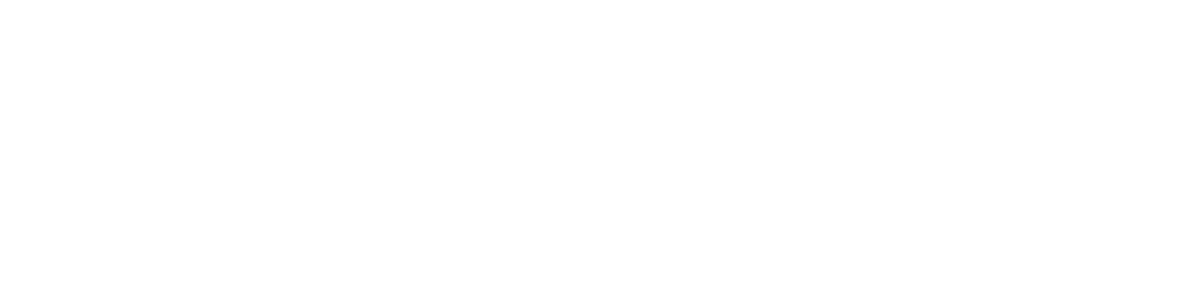

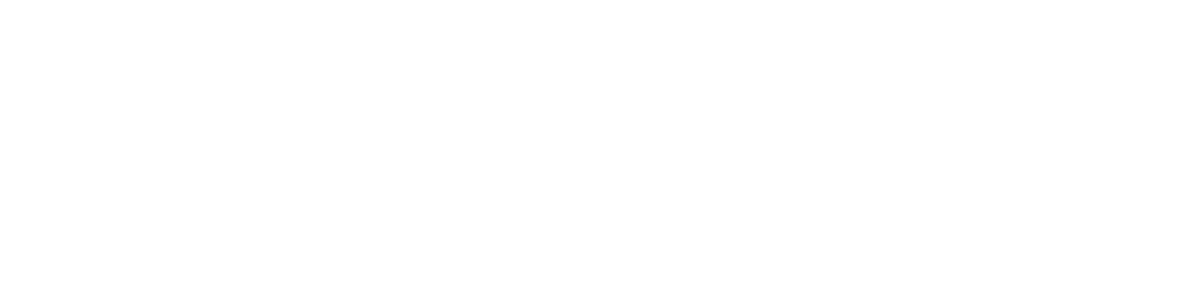

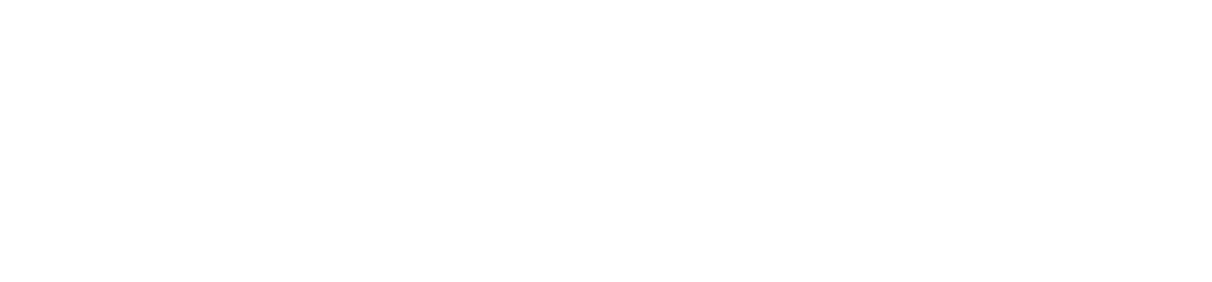

(1)

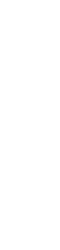

(1)

(n)

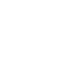

